This is a post-print version of the following article: Hernández, M.I., Couso, D., Pintó, R. (2015). Analyzing students' learning progressions throughout a teaching sequence on Acoustic Properties of Materials with a model-based inquiry approach. Journal of Science Education and Technology, 24 (2), 356-377.

DOI: $10.1007 / \mathbf{s 1 0 9 5 6 - 0 1 4 - 9 5 0 3 - y ~}$

https://link.springer.com/article/10.1007\%2Fs10956-014-9503-y

\title{
Analyzing students' learning progressions throughout a teaching sequence on Acoustic Properties of Materials with a model-based inquiry approach
}

The study we have carried out aims to characterize 15-16-year-old students' learning progressions throughout the implementation of a teaching-learning sequence on the acoustic properties of materials. Our purpose is to better understand students' modeling processes about this topic and to identify how the instructional design and actual enactment influences students' learning progressions. This article presents the design principles which elicit the structure and types of modeling and inquiry activities designed to promote students' development of three conceptual models. Some of these activities are enhanced by the use of ICT such as sound level meters connected to data capture systems, which facilitate the measurement of the intensity level of sound emitted by a sound source and transmitted through different materials. Framing this study within the design-based research paradigm, it consists of the experimentation of the designed teaching sequence with two groups of students $(n=29)$ in their science classes. The analysis of students' written productions together with classroom observations of the implementation of the teaching sequence allowed characterizing students' development of the conceptual models. Moreover, we could evidence the influence of different modeling and inquiry activities on students' development of the conceptual models, identifying those that have a major impact on students' modeling processes. Having evidenced different levels of development of each conceptual model, our results have been interpreted in terms of the attributes of each conceptual model, the distance between students' preliminary mental models and the intended conceptual models, and the instructional design and enactment.

\section{Introduction}

This study aims to characterize 15-16-year-old secondary school students' learning progressions on the acoustic properties of materials (APM) throughout the implementation of an innovative teachinglearning sequence (TLS) (Pintó et al. 2010). Our purpose is to better understand the students' modeling processes when learning about this topic and to identify salient modeling and inquiry activities that influence students' learning progressions. The teaching sequence is largely aimed at promoting students' development of three conceptual models that explain: (1) sound attenuation in materials in terms of energy distribution (CM1); (2) the acoustic behavior of materials in terms of their physical properties (CM2); and (3) the acoustic behavior of materials in terms of their internal structure (CM3). We are particularly interested in understanding the process of students' construction and use of the aforementioned conceptual models as a result of their engagement in the activities that are part of a designed TLS on APM. From the perspective of the design-based research paradigm, we analyze students' learning progressions throughout the designed TLS in order to provide research-based insights for teaching the topic of APM.

\section{Theoretical Framework}

\section{On models and modeling in science and science education}

With the purpose of using a working definition of the term model throughout this article, we explain here our understanding of different terms such as scientific model, conceptual model, and mental model. As defined by Bunge (1973), a scientific model is a representation of a real or conjectured system, consisting of a set of objects with its outstanding properties listed, and a set of law statements that declare the behaviors of these objects. The essential functions of a scientific model, as agreed by many authors (Oh \& Oh, 2011), are descriptions, explanations and predictions. Two types of scientific models can be distinguished from the above definition: theoretical models and empirical models. A theoretical model is 
seen as a scientific model which defines idealized objects (Giere, 1999), whereas an empirical model (or 'model of data') is seen as a scientific model which describes patterns or regularities inferred from observable behaviors of real-world entities or systems (Koponen, 2007). By conceptual model we refer to a representation of physical objects, phenomena, or processes which is not contradictory to scientifically accepted knowledge and is shared by a given community (researchers, teachers, etc.) (Greca \& Moreira, 2000). In science education, a conceptual model is seen as a scientific model that has been didactically transposed to facilitate the understanding of a specific group of students (Acher, Arcà, \& Sanmartí, 2007; Buty, Tiberghien, \& Le Maréchal, 2004). Norman (1983) emphasizes the distinction between conceptual models and mental models, understanding the latter as incomplete and unstable representations that correspond to 'what people really have in their heads and what guide their use of things' (p. 12). Literature has shown that students' mental models can be identical to, similar to, or quite different from the conceptual models that are intended to be taught in science classes.

Currently, many authors in philosophy and history of science and cognitive studies of science consider that the model-based views of scientific knowledge construction and of scientific reasoning are valid for depicting the practice of science (e.g. Giere, 1999; Nersessian, 1995, 1999). These model-based views state that the development of scientific knowledge consists of the progressive or cyclical construction, evaluation and revision of models. Given this model-based philosophical stance towards scientific knowledge development, science education researchers have highlighted the need to promote modelbased pedagogical approaches to teaching and learning science in schools (e.g. Clement, 2000; Gilbert \& Boulter, 1998; Gobert \& Buckley, 2000; Izquierdo-Aymerich \& Adúriz-Bravo, 2003; Tiberghien, 1994). Thus, these pedagogical approaches are grounded on the idea that the particular practices which are integral to the core work of science, and which can consequently offer an authentic scientific experience to learners, are organized around the development and use of conceptual models explaining how the natural world works.

\section{Model-based teaching approach and modeling-based teaching approach}

The model-based teaching approach is a polysemic term in science education: some authors refer to it when talking about teaching and learning the knowledge content of conceptual models; others focus on teaching modeling processes as a scientific practice. We consider that teaching and learning science as a modeling process is essentially different from teaching and learning scientific models in the science classroom. The so-called modeling-based teaching and learning approach (Louca, Zacharia, \& Constantinou, 2011) is more focused on students' construction and refinement of mental models. We agree with Rea-Ramirez, Clement and Núñez-Oviedo (2008), who suggest that any model-based teaching and learning approach in the science classroom should engage students in a modeling process that allows them to reflect on and progressively improve their own mental models through recurring cycles of generation, evaluation and modification, in order to accord with their own thinking and with the data obtained from the external world.

The Two Worlds framework described by Buty et al. (2004) also recognizes that modeling processes play a central part in understanding science by relating descriptions of objects and events in the material world to the world of theories and models. According to these authors, everyday knowledge and scientific knowledge offer ideas and languages for describing objects and events of the material world and these are linked via modeling processes. As stated by Tiberghien, 'the distinction between the world of theories/models and the world of objects/events serves to make explicit the modeling processes that establish relationships between them' (Ruthven, Laborde, Leach, \& Tiberghien, 2009, p. 335).

\section{Model-based inquiry teaching and learning approach}

The model-based teaching approach as a modeling process can be put into practice through different modeling activities, such as the ones described in the literature by Mellar and Bliss (1994). These authors distinguish between two types of modeling activities: exploratory modeling, in which students investigate the properties of conceptual models which are explicitly or implicitly introduced; and expressive modeling, in which students create models to express their own conceptions about particular targets (phenomena, events, mechanisms). Schwarz et al. (2009) propose another classification of modeling instructional activities: exploring phenomena that may necessitate using a model to figure it out, constructing a model, empirically or conceptually testing the model, evaluating the model, revising the model, and using the model to explain and predict. 
Within the literature devoted to modeling processes in science education, we can find some authors (e.g. Justi \& Gilbert, 2002) who include certain inquiry practices (e.g. designing and performing experiments) as part of the modeling process that students carry out in the science class. On the other hand, within the literature devoted to inquiry based science education, we can also find references (e.g. Stewart, Cartier \& Passmore, 2005) to the development of conceptual models as one of the goals of learning by inquiry. For instance, we can highlight the contribution made by Löhner, van Joolingen, Savelsbergh and van Hout-Wolters (2005), who added one type of modeling activity to the two modeling activities described by Mellar and Bliss (1994): inquiry modeling, in which students construct models that allow them to interpret and to predict outcomes from experimenting with phenomena. We also consider that many so-called inquiry activities, such as those highlighted by Minner et al. (2010) - generating / reflecting on scientifically-oriented questions, designing experiments, collecting data, drawing conclusions, and communicating findings - might be also conceived as modeling activities since these two types of activities are often addressed to promote the development of conceptual models.

According to all these authors, at the heart of inquiry there is the careful collection of data, the observation of patterns in the data, and the generation of explanations for those patterns. They claim that the goal of teaching science is twofold: to make students understand the conceptual models that have been generated by that scientific enterprise; and to foster students' abilities to use their knowledge to engage in inquiry and to understand how scientific knowledge is generated and justified.

Thus, several authors (Campbell, Zhang, \& Neilson, 2011; Khan, 2007; Lehrer, Schauble, \& Lucas, 2008; Wells, Hestenes, \& Swackhamer, 1995; Windschitl, Thompson, \& Braaten, 2008) link modeling and inquiry as two related teaching approaches. This integrated teaching approach is usually called model-based inquiry (MBI).

One argument for incorporating this approach in teaching science is put by Buckley (2000), who highlights that students' mental models are not only a source of comprehension but also a source of new questions. She argues that students' evaluation of their own mental models leads them to generate new questions which sustain them in an inquiry cycle of question generation, investigation, and model revision. In line with this, Schwarz and Gwekwerere (2007) propose an instructional framework based on modeling and inquiry activities called EIMA, standing for Engage-Investigate-Model-Apply. These authors state that one of the major tasks in this instructional framework is to explore phenomena and construct and reconstruct models in the light of the results of inquiry activities. However, it is common to find inquiry activities disconnected from science content learning that involve students investigating relationships without considering the possible cause of relationships. We agree with Campbell et al. (2011) that MBI might foster a further connection between inquiry and science content or conceptual models.

We are aware that, as stated by Chinn and Malhotra (2002), modeling-based and inquiry-based teaching could also become epistemologically non-authentic teaching approaches. In particular, many scientific inquiry tasks given to students in schools do not reflect the core attributes of authentic scientific reasoning (Viennot, 2010). Simple inquiry tasks may not only fail to help students learn to reason scientifically but they may also foster a view of scientific reasoning as simple, certain, algorithmic, and focused at a surface level of observation, and science may be viewed as a process of accumulating simple facts about the world. The same could be said of some model-based approaches, which only aim at teaching the knowledge content of scientifically accepted models but not the process of developing them.

In sum, we consider that model-based teaching approaches that do not include inquiry activities such as questioning or design of experiments might result in non-authentic practices that fail in making students aware of relevant aspects of the nature of science. Similarly, some inquiry-based teaching approaches lack of activities devoted to students' development of core scientific knowledge. This has led us to develop a teaching sequence on APM with a MBI approach. We understand the MBI approach as a modeling-based teaching approach which integrates inquiry and modeling school activities that, despite their simplicity, are intended to capture core components of scientific practices.

\section{How is this theoretical framework applied to the design of the teaching-learning sequence on acoustic properties of materials?}

Taking into account the model of educational reconstruction proposed by Duit, Gropengießer and Kattmann (2005), the design of the TLS on APM involved several stages such as the critical analysis of the subject matter to be taught (Hernández et al. 2011), and the analysis of students' preconceptions of sound attenuation and the properties of sound insulating materials (Hernández et al. 2012). This preliminary analysis contributed to our decisions on the order of and connections among the three conceptual models to be taught (CM1, CM2, CM3). Furthermore, we designed the TLS on APM with a MBI approach, integrating the theoretical underpinnings of the frameworks suggested by several authors 
such as the Two Worlds framework (Buty et al., 2004), the types of modeling activities described by Schwarz et al. (2009), the types of inquiry activities described by (Minner et al., 2010), and the emphasis on inquiry activities focused on understanding scientific content (Campbell et al. 2011; Viennot, 2010).

Therefore, the design principles of the TLS on APM are related to:

- The organization of and connections among the conceptual models to be taught: As discussed in the paper published by the Hernández et al. (2012), the analysis of students' preconceptions of sound attenuation and the properties of sound insulating materials gave us insight into how to organize the content to be taught in the TLS in order to facilitate students' development of a more coherent conceptual framework. According to the findings reported in that research study, we decided to organize the teaching of conceptual models starting from the phenomenon of sound attenuation (CM1), followed by the analysis of physical (macro-) properties of sound reflectors and sound absorbers (CM2) and finally, by the analysis of internal (or micro-) structure of these materials (CM3).

- The types of activities selected to configure the MBI approach of the TLS on APM: The teaching sequence integrates modeling and inquiry activities, with a focus to make students' develop, elicit, revise and use conceptual models while at the same time they answer to scientificallyoriented questions, design experiments, collect data, discuss them, draw conclusions and communicate findings.

- The structure of each sequence of tasks: We proposed a common structure in order to design each sequence of tasks intended to contribute to students' development of each conceptual model. This common structure includes the aforementioned modeling and inquiry activities to promote:

(1) Students' elicitation of a preliminary mental model,

(2) Students' revision of their mental models in agreement with new evidence obtained in handson or thought experiments,

(3) Students' revision of their mental models in agreement with the scientific perspective,

(4) Students' use of their revised mental models in a new task

Tables 1, 2, and 3 show how these design principles are applied throughout the TLS and how modeling and inquiry activities are integrated to contribute to students' development of the three conceptual models CM1, CM2, and CM3.

Table 1 summarizes the sequence of tasks intended to contribute to students' development of the conceptual model of sound attenuation in materials (CM1), which allows them:

- To explain how sound attenuation is produced in materials in terms of energy distribution (energy of incident sound, energy of reflected sound, energy of transmitted sound and absorbed energy), and

- To predict the acoustic behavior (sound reflector or sound absorber) of materials in terms of the intensity level that is measured inside a closed space which has been covered with soundattenuating materials.

Table 1 Description of the tasks intended to promote students' development of CM1

\begin{tabular}{|c|c|c|}
\hline TASKS & $\begin{array}{l}\text { MODELLING } \\
\text { ACTIVITIES }\end{array}$ & $\begin{array}{l}\text { INQUIRY } \\
\text { ACTIVITIES } \\
\end{array}$ \\
\hline $\begin{array}{l}\text { T1.1.1) Students are engaged in a problem-based } \\
\text { situation in which they are asked to advise the owner of } \\
\text { a disco on soundproofing according to their own ideas } \\
\text { on the topic } \\
\text { T1.1.2) Students are asked how sound transmission and } \\
\text { sound attenuation happens in the disco context in order } \\
\text { to make them elicit their preliminary models of sound } \\
\text { attenuation in materials }\end{array}$ & $\begin{array}{l}\text { Elicitation of a } \\
\text { preliminary mental } \\
\text { model to explain the } \\
\text { phenomenon of } \\
\text { sound attenuation in } \\
\text { materials }\end{array}$ & $\begin{array}{l}\text { Scientifically- } \\
\text { oriented } \\
\text { questioning }\end{array}$ \\
\hline $\begin{array}{l}\text { T1.3.3) Students perform an experiment using a sound } \\
\text { level meter and a sound source, and investigate the } \\
\text { empirical relationship between the intensity level of } \\
\text { sound propagating through air and the distance between } \\
\text { the sound source and the sound level meter } \\
\text { T1.3.4) Students calculate the attenuated sound from } \\
\text { provided values of intensity level measurements of the } \\
\text { sound emitted inside the disco and the sound transmitted } \\
\text { to the neighboring houses }\end{array}$ & $\begin{array}{l}\text { Revision of the } \\
\text { mental model to be in } \\
\text { agreement with new } \\
\text { evidence obtained in } \\
\text { a hands-on } \\
\text { experiment }\end{array}$ & $\begin{array}{l}\text { Scientifically- } \\
\text { oriented } \\
\text { questioning } \\
\text { Collecting data } \\
\text { Drawing } \\
\text { conclusions from } \\
\text { collected and }\end{array}$ \\
\hline
\end{tabular}


T1.3.5) Students interpret how sound is attenuated in its path from the disco to the neighboring houses

\section{What does science tell us?}

The scientific perspective is introduced by means of a written text and a visual representation in students' worksheets. Students discuss with the teacher and classmates how science explains the process of sound attenuation when sound propagating through air interacts with a solid material.

T1.3.6, T1.3.7 \& T1.3.9) Students are asked to use the scientific perspective in later tasks:

- To explain the acoustic behavior of different materials (sound reflectors and sound absorbers),

- To design and carry out an experiment to test and compare the materials' capacity for attenuating sound, and

- To explain possible solutions for the soundproofing problems of the disco. situations posed in the final assessment

\begin{tabular}{|c|c|}
\hline \multirow{5}{*}{$\begin{array}{l}\text { Revision of the } \\
\text { mental model to be in } \\
\text { agreement with the } \\
\text { scientific perspective }\end{array}$} & $\begin{array}{l}\text { Scientifically- } \\
\text { oriented } \\
\text { questioning }\end{array}$ \\
\hline & $\begin{array}{l}\text { Designing } \\
\text { experiments }\end{array}$ \\
\hline & Collecting data \\
\hline & $\begin{array}{l}\text { Drawing } \\
\text { conclusions from } \\
\text { collected data }\end{array}$ \\
\hline & $\begin{array}{l}\text { Communicating } \\
\text { findings }\end{array}$ \\
\hline \multirow{2}{*}{$\begin{array}{l}\text { Use of the revised } \\
\text { mental model to } \\
\text { explain the } \\
\text { attenuation of sound } \\
\text { and the acoustic } \\
\text { behavior of materials }\end{array}$} & $\begin{array}{l}\text { Scientifically- } \\
\text { oriented } \\
\text { questioning }\end{array}$ \\
\hline & $\begin{array}{l}\text { Drawing } \\
\text { conclusions from } \\
\text { provided data }\end{array}$ \\
\hline
\end{tabular}

Table 2 summarizes the sequence of tasks intended to contribute to students' development of the conceptual model of the acoustic behavior of materials in terms of their physical properties (CM2), which allows them:

- To explain how sound attenuating materials behave in front of sound, taking into account their (acoustic) physical properties (density, rigidity and porosity), and

- To predict the acoustic behavior of materials in terms of their acoustic physical properties (i.e. sound reflectors have high density, high rigidity and no porosity, whereas sound absorbers have low density, low rigidity and porosity).

Table 2 Description of the tasks intended to promote students' development of CM2

\begin{tabular}{|c|c|c|}
\hline TASKS & $\begin{array}{l}\text { MODELLING } \\
\text { ACTIVITIES }\end{array}$ & $\begin{array}{l}\text { INQUIRY } \\
\text { ACTIVITIES }\end{array}$ \\
\hline $\begin{array}{l}\text { T2.1.1) Students elicit their prior ideas on the } \\
\text { properties of materials that affect their acoustic } \\
\text { behavior } \\
\text { T2.1.2) Students agree or disagree with certain } \\
\text { statements that refer to the properties of materials that } \\
\text { affect their acoustic behavior. This activity introduces } \\
\text { new terminology corresponding to materials' } \\
\text { properties that students discuss in small groups. At the } \\
\text { end, students reach a consensus model of sound } \\
\text { reflector and sound absorber in terms of their } \\
\text { properties }\end{array}$ & \multirow[t]{2}{*}{$\begin{array}{l}\text { Elicitation of a } \\
\text { preliminary mental } \\
\text { model to explain the } \\
\text { acoustic behavior of } \\
\text { materials in terms of } \\
\text { their properties }\end{array}$} & \multirow[t]{2}{*}{$\begin{array}{l}\text { Scientifically- } \\
\text { oriented } \\
\text { questioning } \\
\text { Making } \\
\text { predictions }\end{array}$} \\
\hline $\begin{array}{l}\text { T2.1.3) Students apply their consensus model to } \\
\text { predict the acoustic behavior of specific materials }\end{array}$ & & \\
\hline $\begin{array}{l}\text { T2.1.4 \& T2.1.5) Students investigate the relationship } \\
\text { between certain properties of different materials and } \\
\text { their acoustic behavior by designing and carrying out } \\
\text { an experiment }\left({ }^{a}\right) \text { that allows testing the previous } \\
\text { predictions. }\end{array}$ & $\begin{array}{l}\text { Revision of the mental } \\
\text { model to be in } \\
\text { agreement with new } \\
\text { evidence obtained in } \\
\text { observations and a }\end{array}$ & $\begin{array}{l}\text { Scientifically- } \\
\text { oriented } \\
\text { questioning } \\
\text { Designing an }\end{array}$ \\
\hline
\end{tabular}


T2.1.6) In the light of the results of the experiment, students classify the tested materials in two groups: sound reflectors and sound absorbers. Then, students observe and manipulate these materials and describe the properties that each group have in common hands-on experiment experiment

Collecting data

Drawing

conclusions from

collected data

Scientifically-

oriented

questioning

model to be in

agreement with the

scientific perspective

and with new evidence

Drawing

conclusions from

provided data and observations students analyze more accurate data of certain properties of the tested materials

Use of the revised mental model to explain and predict the acoustic behavior of materials in terms of their properties
Scientifically-

oriented

questioning

Drawing conclusions from provided data

$\left({ }^{a}\right)$ This experiment consists of using a sound level meter connected to a data capture system in order to measure the sound intensity level produced by a sound source (e.g., a buzzer) that has been placed inside a cardboard box whose walls have been covered with a certain material. The box represents the structure of a room or closed space where there is a sound source and the material that covers the walls represent the material used to soundproof that room. This measurement is compared with the reference value, measured within the box when the box is not covered with any material. If the sound intensity level measured within the box covered with a material is higher than the reference value, then we can conclude that the material behaves as a sound reflector. If the measured value is lower than the reference value, we can conclude that the material behaves as a sound absorber. For more details about the experiment, see Hernández et al. (2011).

Table 3 summarizes the sequence of tasks intended to contribute to students' development of the conceptual model of the acoustic behavior of materials in terms of their internal structure (CM3), which allows them:

- To explain the mechanisms of sound attenuation in materials using the particle model of matter in terms of more or less vibration of the particles that form each material, and

- To relate the acoustic behavior of materials to their physical properties and to relate these properties to the mass and arrangement of their particles and the strength of their bonds.

Table 3 Description of the tasks intended to promote students' development of CM3

\begin{tabular}{|c|c|c|}
\hline TASKS & $\begin{array}{l}\text { MODELLING } \\
\text { ACTIVITIES }\end{array}$ & $\begin{array}{l}\text { INQUIRY } \\
\text { ACTIVITIES }\end{array}$ \\
\hline $\begin{array}{l}\text { T2.1.1) Students elicit their prior ideas on the } \\
\text { characteristics of materials that affect their acoustic } \\
\text { behavior } \\
\text { T2.1.2) Students agree or disagree with certain } \\
\text { statements that refer to the influence of the internal } \\
\text { structure of materials on their acoustic behavior. This } \\
\text { activity introduces new terminology and new } \\
\text { perspectives that students discuss with their classmates }\end{array}$ & $\begin{array}{l}\text { Elicitation of a } \\
\text { preliminary mental model } \\
\text { to explain the acoustic } \\
\text { behavior of materials in } \\
\text { terms of their internal } \\
\text { structure }\end{array}$ & $\begin{array}{l}\text { Scientifically- } \\
\text { oriented } \\
\text { questioning }\end{array}$ \\
\hline $\begin{array}{l}\text { T2.2.1, T2.2.2, T2.2.3, T2.2.4 \& T2.2.5) Students } \\
\text { investigate the relationship between the internal } \\
\text { structure of materials and their acoustic behavior using } \\
\text { the ball-and-spring model and an analogy }\left({ }^{b}\right) \text {. Students } \\
\text { are then expected to transfer the language and } \\
\text { reasoning used with the analogy to explain how } \\
\text { density, rigidity and porosity of materials can be }\end{array}$ & $\begin{array}{l}\text { Revision of the mental } \\
\text { model to be in agreement } \\
\text { with new evidence } \\
\text { obtained in a thought } \\
\text { experiment }\end{array}$ & $\begin{array}{l}\text { Scientifically- } \\
\text { oriented } \\
\text { questioning } \\
\text { Thought } \\
\text { experiment }\end{array}$ \\
\hline
\end{tabular}


conceptualized at the level of their internal structure

Drawing

and how these properties affect their acoustic behavior

conclusions

\section{What does science tell us?}

The scientific perspective is introduced by means of a written text in students' worksheets. Students discuss with the teacher and the classmates the scientific view on how the properties and internal structure of sound absorbers affect their acoustic behavior

T2.2.6 \& T2.2.7) Students use the same line of reasoning to explain how the properties and internal structure of specific materials affect their acoustic behavior

Revision of the mental model to be in agreement with the scientific perspective
Scientificallyoriented questioning
Q5.b) Students apply their revised mental models to novel situations posed in the final assessment
Use of the revised mental model to explain the acoustic behavior of materials in terms of their internal structure
Scientificallyoriented questioning

$\left(^{b}\right)$ This analogy compares particles that form each medium or material with pool balls connected by means of springs. According to this analogy, density is related to the mass of the balls and rigidity is related to the elastic constant of the springs connecting the balls. According to the ball-and-spring model, porosity is related to the presence of air particles inside the pores of a material, which is also formed by bonded particles with a different mass.

\section{Research Questions}

We agree with Anderson (2002, p. 6) that 'research on inquiry-based science education has matured and tended to move away from the question of whether or not inquiry teaching is effective and has become focused more on understanding the dynamics of such teaching and how it can be brought about'. On the other hand, we also recognize that crucial information is still missing in published research studies regarding the process that students follow throughout a TLS with a model-based pedagogical approach, as stated by Louca et al. (2011).

The same could be said about MBI as an instructional strategy to teach science since 'there remains little published research investigating the nuances and outcomes of this (pedagogical) approach when implemented in secondary science classrooms' (Campbell et al., 2011, p. 261).

Taking into account the issues highlighted above and framing our research within the design-based research paradigm (DBR), this study will devote particular attention to experimenting with the designed TLS on APM in order to explain: (1) the dynamics of students' development of conceptual models on sound attenuation and the acoustic properties of materials throughout the implementation of the designed teaching sequence; and (2) the influence of the modeling and inquiry activities of the TLS on students' learning progressions. In particular, we will try to answer the following research questions:

(1) How do students progress from their preliminary mental models of sound attenuation in materials and of the acoustic behavior of materials towards the intended conceptual models throughout the implementation of the TLS on APM?

(2) How do the modeling and inquiry activities of the designed TLS contribute to the students' development of the intended conceptual models?

The answer to these questions will help us to better understand how the designed teaching sequence works in two real classrooms. This will allow us to analyze the principles (DBR Collective, 2003; Tiberghien, Vince, \& Gaidioz, 2009) that guided the design of the structure of the TLS on APM with a MBI approach on the basis of collected evidence.

\section{Methodology of Research}

\section{Context of Research}

The research presented here was carried out within the context of the implementation of the designed TLS on APM. The design and iterative development of this TLS (Hernández and Pintó, in press) was carried out during three consecutive years (2007 to 2009) by three researchers in science education and six experienced secondary school teachers (one physics graduate and five chemistry graduates) from four different schools. The development of the teaching sequence was based on a strong university-school 
collaboration emphasizing a participatory view of curriculum design (Couso, in press) in order to promote learning on the part of all members and to avoid critical transformations (Pintó 2005; Viennot, Chauvet, Colin, \& Rebmann, 2005) of the innovation when it was implemented.

The designed TLS on APM was planned to be implemented in ordinary schools with tenth-graders (15-16-year-old students) within the science subject 'physics and chemistry'. In the Spanish educational context tenth grade is the last compulsory academic year for students under 16 years old and it is also the first grade in which the study of physics and chemistry is optional. The official physics and chemistry syllabus for the last year of compulsory secondary school, which suggests a qualitative and phenomenological study of the contents, includes the following key topics: sound waves, and the structure and properties of matter, among others. These particular topics were studied by students before the implementation of the innovative sequence on APM.

Regarding the implementation of the TLS, it is important to mention that all the teachers involved in the implementation in our context were used to teaching by questioning rather than by telling, and to encouraging students to work in groups. However, most of these teachers were not very familiar with the MBI pedagogical approach and were interested in developing more teaching strategies to move towards this approach. For this reason, they were involved in the design, implementation and later refinement of the TLS and, during all this process they were supported inside and outside the classroom by the researchers involved in the development of the TLS. After participating in the implementation and refinement of consecutive versions of the TLS during three years, researchers could observe that the pedagogical approach and the content of the TLS did not present a major challenge to these teachers when implementing the third (and most refined) version of the TLS.

The conditions under which this third version of the TLS was implemented and the research data were collected for this study correspond to the ordinary context of these teachers' science classes. As not all the teachers involved in the design could implement this third and last version - resulting from several refinements - of the designed TLS at the same academic level, for the purposes of the research presented here we reduced our sample to 29 secondary school students (15-16-year-olds), who belong to two different class groups. The two teachers who could implement the whole sequence at this academic level devoted a similar number of hours / days ( 12 to 15, one hour each day, 3 to 4 hours a week) and followed the written teaching and learning material as it was structured. Both of them tended to interact with the whole class group at the beginning of each session - to present the aims of the session - and at the end of it - to summarize together with students the conclusions of the lesson. During most part of each session both teachers tended to promote collaborative work and active discussion among their students while they approached to each group to listen to them and to ask further questions. Table 4 presents a general description of each of the schools to which these class groups belong as well as the number of students who constitute our sample.

Table 4 General description of the sample

\begin{tabular}{clc}
\hline School & \multicolumn{1}{c}{ Description of the school } & Number of students $\left(^{c}\right)$ \\
\hline A & $\begin{array}{l}\text { State secondary school in an urban area } \\
\text { Medium-high socio-economic background of students } \\
\text { Low number of immigrant students } \\
\text { Low number of gifted students and those with special } \\
\text { educational needs }\end{array}$ & 12 \\
\hline Privately-run school funded by the state in a small town \\
Medium-high socio-economic background of students \\
Low number of immigrant students \\
Low number of gifted students and those with special \\
educational needs
\end{tabular}

$\left({ }^{c}\right)$ The number of students in each class group corresponds to the total number of 15-16 year-old students who chose to study physics and chemistry at this level.

\section{Data collection}

With the purpose of analyzing students' development of conceptual models, different learning and assessment tasks were collected. These tasks are domain-specific since they allow collecting data in the domain of acoustic properties of materials. The collected data correspond to students' written answers to several learning tasks, included in the worksheets that students completed during the implementation of the sequence, and to students' responses to several questions, included in the final assessment. All students answered each of the learning tasks in their worksheets individually although some of these tasks 
required collaborative work among students and/or class discussions with the teacher, and so we assume that some written answers are the result of these student-teacher and student-student interactions. Students' responses to the questions included in the final assessment were all individual.

As this research study is framed within the design-based research paradigm, we planned to collect data in naturalistic settings. Therefore, the learning and assessment tasks were part of the designed teaching sequence. As described before, this TLS had been already implemented and refined two times before the third implementation took place, when the data for the present research study were collected. Therefore, the tasks and questions used to collect data had been already tested with 15-16 year-old students in real contexts and, in some cases they had been consequently reviewed to avoid misinterpretations and to collect relevant data. This procedure contributed to increase the validity of the instruments of data collection. Reliability of findings and measures was promoted not only through creation of refined and validated instruments, but also through triangulation on the part of the three authors of this study, who used the same categories to analyze students' responses, discussed them and refined them to make them more operational and clearer. Authors' agreement on the findings after analysis and discussion contributed to enhance inter-rater reliability of these findings. Finally, data coming from classroom observations on how the tasks were carried out in class also contributed to increase the reliability of findings. Although the analyzed data came from students' written answers, observations served to collect evidence on the conditions under which the implementation of the tasks took place in class, with regards to the structure of the designed teaching sequence. The data collected through observations took into account the types and content of interactions among teacher and students and among students throughout each lesson, and modifications, if any, to the structure or content of the teaching sequence introduced by a teacher during her/his interventions.

Table 5 specifies the tasks embedded in the TLS that were used to collect evidence on the development of each of the three conceptual models.

Table 5 Tasks and questions to collect evidence of students' development of each conceptual model

\begin{tabular}{|c|c|c|c|c|}
\hline \multirow[b]{2}{*}{$\begin{array}{l}\text { Conceptual } \\
\text { model }\end{array}$} & \multicolumn{4}{|c|}{ Tasks and questions to collect evidence $\left({ }^{d}\right)$} \\
\hline & $\begin{array}{l}\text { Elicitation of } \\
\text { preliminary } \\
\text { models }\end{array}$ & $\begin{array}{l}\text { Revision of the mental model } \\
\text { to be in agreement with new } \\
\text { evidence obtained in hands- } \\
\text { on or thought experiments }\end{array}$ & $\begin{array}{c}\text { Revision of the } \\
\text { mental model to be } \\
\text { in agreement with } \\
\text { the scientific } \\
\text { perspective } \\
\end{array}$ & $\begin{array}{l}\text { Use of } \\
\text { revised } \\
\text { models }\end{array}$ \\
\hline CM1 & $\begin{array}{l}\text { T1.1.2.a } \\
\& \\
\text { T1.1.2.c }\end{array}$ & T1.3.5 & $\begin{array}{c}\mathrm{T} 1.3 .6 \\
\& \\
\mathrm{~T} 1.3 .7 \\
\& \\
\mathrm{~T} 1.3 .9 \\
\end{array}$ & $\begin{array}{c}\text { Q2 } \\
\& \\
\text { Q4.c } \\
\& \\
\text { Q5.b }\end{array}$ \\
\hline CM2 & $\begin{array}{c}\mathrm{T} 2.1 .1 \\
\& \\
\mathrm{~T} 2.1 .2 . \mathrm{c} \\
\& \\
\mathrm{~T} 2.1 .3 \\
\end{array}$ & T2.1.6.b & $\mathrm{T} 2.1 .8$ & $\begin{array}{l}\text { Q4.a } \\
\& \\
\text { Q5.a }\end{array}$ \\
\hline CM3 & $\begin{array}{l}\mathrm{T} 2.1 .1 \\
\& \\
\mathrm{~T} 2.1 .2\end{array}$ & $\begin{array}{c}\text { T2.2.2 } \\
\& \\
\text { T2.2.4 } \\
\& \\
\mathrm{~T} 2.2 .5 \\
\end{array}$ & $\begin{array}{c}\text { T2.2.6 } \\
\& \\
\text { T2.2.7 }\end{array}$ & Q5.b \\
\hline $\begin{array}{l}\text { (d) T refers to } \\
\text { the TLS. Q re } \\
\text { statements of }\end{array}$ & s included in & $\begin{array}{l}\text { dents' worksheets and carried } \\
\text { d in the written final assessmer } \\
\text { ons can be found in the Online }\end{array}$ & $\begin{array}{l}\text { throughout the imple } \\
\text { The written material } \\
\text { source } 1\end{array}$ & $\begin{array}{l}\text { tation o } \\
\text { ding th }\end{array}$ \\
\hline
\end{tabular}

\section{Data Analysis}

In order to answer our research questions, we decided to explore students' learning progressions throughout the designed TLS, using an interpretative qualitative approach. Tracking students' progressions all through the teaching-learning process of specific teaching-learning interventions has gained prominence in science education over the last decades as many scholars agree that learning ought 
to be coordinated and sequenced along learning progressions ${ }^{1}$ (Driver, Leach, Scott, \& Wood-Robinson, 1994; Duschl, Maeng \& Sezen, 2011; Niedderer \& Goldberg, 1995; Schwarz et al., 2009; Scott, 1991; Talanquer, 2009; Viennot \& Rainson, 1999). These learning progressions are generally viewed by researchers as conjectural or hypothetical model pathways of learning over periods of time that need to be empirically validated in the light of research on students' progress (Duschl et al., 2011).

Before any implementation took place, each conceptual model that was intended to be developed by students throughout the designed TLS on APM was expressed in terms of a set of learning objectives (LO). Each set of learning objectives is therefore an expression of a conceptual model in a very specific and observable format. Table 6 shows the list of learning objectives associated with each conceptual model to be developed by the students throughout the implementation of the TLS on APM.

Table 6 Intended learning objectives associated with each conceptual model

\begin{tabular}{ll} 
LO\# & Description of each learning objective associated with CM1 \\
\hline LO1.1 & To recognize that sound is distributed in different parts when reaching an object \\
LO1.2 & To recognize that part of sound is reflected \\
LO1.3 & To recognize that part of sound is absorbed \\
LO1.4 & To identify both reflection and absorption as mechanisms of sound attenuation \\
LO1.5 & $\begin{array}{l}\text { To (qualitatively and/or quantitatively) associate sound attenuation with the decrease in the } \\
\text { intensity level of the incident sound when it is transmitted }\end{array}$ \\
LO1.6 & To explain/interpret that sound attenuation involves energy transfer/distribution \\
\hline LO2.1 & $\begin{array}{l}\text { To identify properties related to density (e.g. density, compactness) of materials as one of the } \\
\text { properties that influence the acoustic behavior of materials }\end{array}$ \\
LO2.2 & $\begin{array}{l}\text { To identify properties related to rigidity (e.g. hardness, elasticity) of materials as one of the } \\
\text { properties that influence the acoustic behavior of materials } \\
\text { LO2.3 }\end{array}$ To identify porosity as one of the properties that influence the acoustic behavior of materials \\
LO2.4 & $\begin{array}{l}\text { To relate density appropriately to the acoustic behavior of materials (i.e. the more dense they } \\
\text { are, the more sound reflect; the less dense they are, the more sound absorb) }\end{array}$ \\
LO2.5 & $\begin{array}{l}\text { To relate rigidity appropriately to the acoustic behavior of materials (i.e. the more rigid they } \\
\text { are, the more sound reflect; the less rigid they are, the more sound absorb) }\end{array}$ \\
LO2.6 & $\begin{array}{l}\text { To relate porosity appropriately to the acoustic behavior of materials (i.e. the more porous they } \\
\text { are, the more sound absorb; the less porous they are, the more sound reflect) }\end{array}$ \\
To explain the acoustic behavior of materials uniquely in terms of their density, rigidity and \\
porosity (not other properties) and relate them appropriately to the acoustic behavior of \\
materials
\end{tabular}

\section{Description of each learning objective associated with CM3}

\begin{tabular}{ll}
\hline LO3.1 & To relate the acoustic behavior of materials to their internal structure \\
LO3.2 & To describe density, rigidity and porosity of materials in terms of their microstructure \\
LO3.3 & To use the particle model of matter to explain mechanisms of sound attenuation in materials \\
LO3.4 & $\begin{array}{l}\text { To describe density, rigidity or porosity of materials appropriately in terms of their } \\
\text { microstructure } \\
\text { LO3.5 }\end{array}$ \\
To use the particle model of matter appropriately to explain mechanisms of sound attenuation \\
in materials
\end{tabular}

From the collected data, we proceeded to analyze students' achievement of each learning objective at different moments of the implementation of the TLS with a twofold aim: (1) to evaluate the degree of students' development of each conceptual model at the end of the implementation compared with their starting mental models, and (2) to evidence the intermediate models that were built by students at each stage of the implementation. Thus, we did not expect to describe the effectiveness of the implementation of the TLS but several stages of progress (Corcoran, Mosher, \& Rogat, 2009, p.15), which would characterize significant intermediate steps or stepping-stones in the development of increasingly elaborate students' mental models. These stepping-stones allow students to move from 'lower anchors', which

\footnotetext{
${ }^{1}$ Some of the former work on learning pathways has been recently restructured and expanded to the notion of learning progressions. Learning progressions have been referred to by many terms, including conceptual / learning trajectories, conceptual progressions, or profile strands.
} 
represent the knowledge students bring with them to school, towards 'upper anchors', which represent our expectations of what students should know and be able to do at the end of the instruction.

With the purpose of characterizing students' intermediate models towards the intended conceptual models, we carried out the following analysis protocol:

- Coding of students' answers to each task from their worksheets and question from the exam selected for data collection (Table 5). A different number was assigned to each student and to each task or question.

- Interpretation of students' achievement (or not) of each learning objective from students' answers to each task / question. As shown in Table 5, each task / question is associated with a certain phase of the implementation of the TLS and a certain type of activity (i.e. elicitation of preliminary models, revision of the mental model to be in agreement with new evidence obtained in hands-on or thought experiments, revision of the mental model to be in agreement with the scientific perspective, use of revised models).

- Analysis of the percentage of students' achievement of each learning objective associated with each intended conceptual model.

- Grouping of the subsets of learning objectives that had been achieved by most students achieved at each phase of the implementation of the TLS.

- Description of students' most representative mental model at each stage in terms of these subsets learning objectives acquired by most of students (Second column Table 7).

- Elaboration of empirically-based categories developed to characterize students' mental models towards each intended conceptual model (First column Table 7).

- Analysis of the percentage of each student's mental model at each phase of the implementation of the TLS.

Tables 7, 8, and 9 show the description of these emergent categories that characterize students' stages of development of conceptual models CM1, CM2, and CM3. These tables also include students' answers to illustrate students' mental models which are progressively more elaborate.

Table 7 Description of the stages of development of CM1 and students' answers

\begin{tabular}{|c|c|c|}
\hline $\begin{array}{c}\text { Stage of } \\
\text { development of } \\
\text { CM1 } \\
\end{array}$ & Description of students' models & Examples of students' answers \\
\hline S1 & $\begin{array}{l}\text { Students explain sound attenuation in a } \\
\text { material as the decrease in sound intensity } \\
\text { level resulting from the distribution of sound } \\
\text { in different components such as transmitted } \\
\text { sound and reflected sound - LO1.1, LO1.2 } \\
\text { \& LO1.5 }\end{array}$ & $\begin{array}{l}\text { [When sound emitted by } \\
\text { loudspeakers reaches the walls of a } \\
\text { disco] it bounces back and some goes } \\
\text { outside the disco through the wall }\end{array}$ \\
\hline S2 & $\begin{array}{l}\text { Students explain sound attenuation in a } \\
\text { material as the decrease in sound intensity } \\
\text { level resulting from the distribution of sound } \\
\text { in different components such as transmitted } \\
\text { sound and absorbed sound - LO1.1, LO1.3 } \\
\text { \& LO1.5 }\end{array}$ & $\begin{array}{l}\text { [The part of sound that is not } \\
\text { transmitted through the walls] has } \\
\text { been absorbed by the walls }\end{array}$ \\
\hline S3 & $\begin{array}{l}\text { Students explain sound attenuation in a } \\
\text { material as the decrease in sound intensity } \\
\text { level resulting from the distribution of sound } \\
\text { in different components such as transmitted } \\
\text { sound, reflected sound and absorbed } \\
\text { sound - LO1.1, LO1.4 \& LO1.5 }\end{array}$ & $\begin{array}{l}\text { [The part of sound that is not } \\
\text { transmitted through the walls] has } \\
\text { been reflected or absorbed by the } \\
\text { walls }\end{array}$ \\
\hline S4 & $\begin{array}{l}\text { Students explain sound attenuation in a } \\
\text { material as the decrease in sound intensity } \\
\text { level resulting from the distribution of } \\
\text { energy of sound in different components } \\
\text { such as the energy of transmitted sound, the } \\
\text { energy of reflected sound and the absorbed } \\
\text { energy- LO1.1, LO1.4, LO1.5 \& LO1.6 }\end{array}$ & $\begin{array}{l}\text { To increase sound attenuation in the } \\
\text { neighbors' house, the energy and the } \\
\text { intensity of sound must decrease. To } \\
\text { do so, the walls need to be made of } \\
\text { good sound absorbers and insulators } \\
\text { so that absorption and reflection of } \\
\text { sound are higher }\end{array}$ \\
\hline
\end{tabular}

Table 8 Description of the stages of development of CM2 and students' answers 


\begin{tabular}{|c|c|c|}
\hline $\begin{array}{c}\text { Stage of } \\
\text { development of } \\
\text { CM2 } \\
\end{array}$ & Description of students' models & Examples of students' answers \\
\hline S1 & $\begin{array}{l}\text { Students explain and predict the } \\
\text { acoustic behavior of materials in terms } \\
\text { of intensive and extensive properties, } \\
\text { such as density and rigidity, although } \\
\text { these terms are not used } \\
\text { appropriately - LO2.1 \& LO2.2 }\end{array}$ & $\begin{array}{l}\text { Sound reflectors are elastic, dense and } \\
\text { have light colors whereas sound } \\
\text { absorbers are plastic, soft and have } \\
\text { dark colors }\end{array}$ \\
\hline $\mathbf{S 2}$ & $\begin{array}{l}\text { Students explain and predict the } \\
\text { acoustic behavior of materials in terms } \\
\text { of intensive and extensive properties, } \\
\text { such as density, rigidity, and } \\
\text { porosity, although these terms are not } \\
\text { used appropriately - LO2.1, LO2.2 } \\
\text { \& LO2.3 }\end{array}$ & $\begin{array}{l}\text { Sound reflectors are dense, thick and } \\
\text { have many particles and a smooth } \\
\text { surface whereas sound absorbers are } \\
\text { porous, soft, flexible and have } \\
\text { separated particles }\end{array}$ \\
\hline S3 & $\begin{array}{l}\text { Students adequately explain and } \\
\text { predict the acoustic behavior of } \\
\text { materials in terms of intensive and } \\
\text { extensive properties, such as density, } \\
\text { rigidity, and porosity, using these } \\
\text { terms appropriately - LO2.1, LO2.2, } \\
\text { LO2.3, LO2.4, LO2.5 \& LO2.6 }\end{array}$ & $\begin{array}{l}\text { Aluminum would behave as a sound } \\
\text { reflector because it is not porous, it is } \\
\text { dense and its surface is smooth. } \\
\text { Polyurethane would behave as a sound } \\
\text { absorber because it is not very dense } \\
\text { and it has holes }\end{array}$ \\
\hline S4 & $\begin{array}{l}\text { Students adequately explain and } \\
\text { predict the acoustic behavior of } \\
\text { materials uniquely in terms of } \\
\text { intensive properties, such as density, } \\
\text { rigidity, and porosity, using these } \\
\text { terms appropriately - LO2.7 }\end{array}$ & $\begin{array}{l}\text { Material A would be the best sound } \\
\text { reflector as it is dense, rigid and non- } \\
\text { porous. Material C would be the best } \\
\text { sound absorber because it is less dense, } \\
\text { it is flexible and it has pores which } \\
\text { facilitate sound propagation }\end{array}$ \\
\hline
\end{tabular}

Table 9 Description of the stages of development of CM3 and students' answers

\begin{tabular}{|c|c|c|}
\hline $\begin{array}{c}\text { Stage of } \\
\text { development of } \\
\text { CM3 } \\
\end{array}$ & Description of students' models & Examples of students' answers \\
\hline S1 & $\begin{array}{l}\text { Students explain the acoustic behavior of } \\
\text { materials using the particle model of } \\
\text { matter and explaining inadequate } \\
\text { mechanisms of sound attenuation in } \\
\text { materials, that tend to depict sound as a } \\
\text { substance or physical entity - LO3.1, } \\
\text { LO3.2 \& LO3.3 }\end{array}$ & $\begin{array}{l}\text { If the material is porous it will } \\
\text { behave as a sound absorber as its } \\
\text { particles are more separated, and so } \\
\text { the material has empty spaces } \\
\text { through which sound can enter }\end{array}$ \\
\hline S2 & $\begin{array}{l}\text { Hybrid stage between } \mathbf{S 1} \text { and S3: } \\
\text { students use both the preliminary (S1) } \\
\text { and the more elaborate (S3) version of } \\
\text { the model to explain the influence of } \\
\text { certain characteristics of the material on } \\
\text { their acoustic behavior }\end{array}$ & $\begin{array}{l}\text { The fact that this material has low } \\
\text { density means that its particles are } \\
\text { more separated, and therefore sound } \\
\text { can enter this material; that is to say, } \\
\text { sound can be absorbed. The material } \\
\text { is also very flexible and therefore its } \\
\text { particles can move more }\end{array}$ \\
\hline S3 & $\begin{array}{l}\text { Students explain the acoustic behavior of } \\
\text { materials using the particle model of } \\
\text { matter and appropriately explaining } \\
\text { mechanisms of sound attenuation in } \\
\text { materials - LO3.1, LO3.4 \& LO3.5 }\end{array}$ & $\begin{array}{l}\text { As the material is porous, not very } \\
\text { dense and flexible, its particles can } \\
\text { vibrate a lot, and so the material } \\
\text { absorbs sound }\end{array}$ \\
\hline
\end{tabular}

Furthermore, the analysis of each student's development of each intended conceptual model at each stage of the implementation of the TLS allowed us to infer a bottom-up learning progression that describes the most representative students' learning progression towards the development of each conceptual model. We tracked the evolution of each student's development of each conceptual model to illustrate whether each of them experienced progression, regression or no evolution as a result of their engagement in each activity of the TLS. Then, we analyzed the percentage of each type of students' 
evolution comparing their mental models before and after each activity during the implementation of the TLS. That is to say, the predominant learning progression is grounded and built on the analysis of the evidence of students' learning that has been obtained, instead of simply being based on a logical task analysis of content domains and personal experiences with teaching (Duschl et al., 2011).

Finally, we relate students' learning outcomes to specific features of the designed TLS in order to analyze how specific instruction factors help students progress from lower to higher levels of understanding. As Duschl, et al. (2011) observe, details about the instructional interventions that might influence how students progress are often missing in published research studies of students' learning. In this sense, the characterization of students' evolution of their mental models allows us to analyze the influence of each modeling and inquiry activity of the designed TLS, as it was implemented in class, on students' development of the three conceptual models described above.

\section{Results}

\section{Students' development of the theoretical conceptual model of sound attenuation in materials in terms of energy (CM1)}

As described earlier, the analysis of the students' development of each conceptual model took into account the results of a preliminary analysis of students' achievement of specific learning objectives to characterize later students' mental models in terms of their learning outcomes.

Students' achievement of each learning objective associated with the conceptual model of sound attenuation in materials in terms of energy (CM1)

The findings of the analysis of students' achievement of learning objectives associated with the conceptual model of sound attenuation in materials in terms of energy (CM1) at different moments of the implementation of the TLS are illustrated in Table 10.

Table 10 Learning objectives related to students' development of the CM1

\begin{tabular}{|c|cccc|}
\hline LO - & T1.1.2.a \& & T1.3.5 & T1.3.6 \& T1.3.7 \& & \multirow{2}{*}{ Q2 \& Q4.c \& Q5.b } \\
CM1 & T1.1.2.c & $75 \%$ & $95 \%$ & $93 \%$ \\
LO1.1 & $96 \%$ & $58 \%$ & $95 \%$ & $93 \%$ \\
LO1.2 & $92 \%$ & $42 \%$ & $95 \%$ & $89 \%$ \\
LO1.3 & $23 \%$ & $25 \%$ & $95 \%$ & $86 \%$ \\
LO1.4 & $19 \%$ & $-\left(^{\mathrm{e}}\right)$ & $89 \%$ & $82 \%$ \\
LO1.5 & $62 \%$ & $0 \%$ & $68 \%$ & $68 \%$ \\
LO1.6 & $12 \%$ & & & T1.3.9 \\
\hline
\end{tabular}

(e) It was not possible to track the students' achievement of this specific learning objective in this activity

As shown in Table 10, at the beginning of the implementation of the TLS on APM (T1.1.2.a and T1.1.2.c) more than $90 \%$ of students were already able to recognize that sound is distributed in different components when reaching an object such as a wall (LO1.1). Nevertheless, most students only identified transmitted sound and reflected sound as the components in which incident sound is distributed (LO1.2). Only $23 \%$ of students identified absorption as a mechanism of sound attenuation (LO1.3). On the other hand, while almost two-thirds of the students already associated sound attenuation in materials with the decrease in the intensity level of the incident sound when it is transmitted through a material (LO1.5), only $12 \%$ of students associated sound attenuation with the distribution of energy (LO1.6).

The analysis of students' responses to the intermediate task T1.3.5, after performing an experiment and discussing it in class, indicated that the number of students who recognized absorption within the medium as a possible mechanism of sound attenuation (LO1.3) increased (42\%), whereas the percentage of students who identified reflection decreased (58\%). Nevertheless, these results also illustrate that most students $(75 \%)$ were not able to identify both reflection and absorption as mechanisms of sound attenuation (LO1.4) and none of them interpreted sound attenuation produced through a material in terms of energy distribution (LO1.6).

After T1.3.5 students were faced with a text and a visual representation that (verbally and diagrammatically) explained how science interprets the process of sound attenuation when sound propagating through air interacts with a solid material. After discussing the text and the visual representation with their teacher and peers, students proceeded to perform other tasks (T1.3.6, T1.3.7 and T1.3.9). The answers to these tasks give evidence of an increase of up to about $90 \%$ of students who were able to identify both reflection and absorption as mechanisms of sound attenuation (LO1.4) and to 
associate sound attenuation appropriately with the decrease in the intensity level of the incident sound when transmitted (LO1.5). Moreover, the analysis of students' responses also illustrated that more than two-thirds of students $(68 \%)$ were able to explain or interpret that sound attenuation involves distribution of energy (LO1.6).

Finally, the questions posed in the final assessment reveal similar levels of students' achievement of the learning objectives associated with CM1. At that point, about $90 \%$ of students were able to identify both reflection and absorption as mechanisms of sound attenuation (LO1.4), about $80 \%$ of students were able to associate sound attenuation appropriately with the decrease in the intensity level of the incident sound when transmitted (LO1.5) and almost $70 \%$ of students were able to explain or interpret that sound attenuation involves distribution of energy (LO1.6).

Students' stages of development of the conceptual model of sound attenuation in materials in terms of energy (CM1) at each phase of the TLS

Using the categories presented in Table 7 to characterize students' stages of development of CM1, we analysed the distribution of students in each stage of development of CM1 throughout the implementation of the TLS on APM. This distribution is represented in Figure 1.

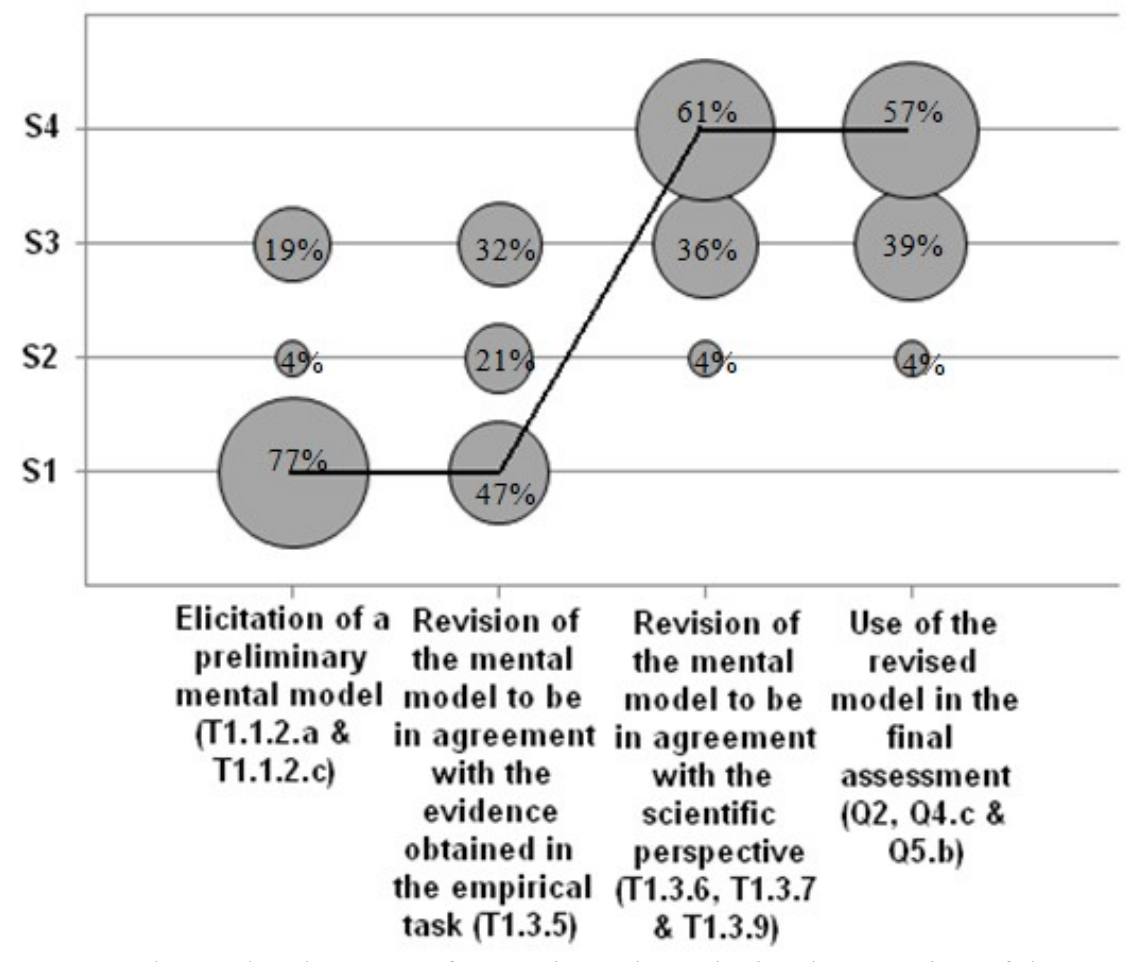

Fig. 1 Students' development of CM1 throughout the implementation of the TLS

Moreover, Figure 1 shows the most representative students' learning progression towards the construction of the intended conceptual model of sound attenuation in materials (CM1) throughout the implementation of the TLS on APM. The most representative learning progression is highlighted with a straight line. The diameter of each circle represents the percentage of students in each stage of development of CM1 at different moments of the implementation of the TLS. Therefore, Figure 1 also shows that most students followed a certain learning progression whereas other students followed different learning progressions.

In Figure 1, we can see that at the beginning of the implementation of the teaching sequence, most students $(77 \%)$ elicited a mental model that explains sound attenuation in materials as the decrease in the intensity level of incident sound resulting from the distribution of sound in different components such as transmitted sound and reflected sound. We consider this students' preliminary mental model as the first stage (S1) or starting point which is more representative in the process of students' development of CM1.

After the experiment (T1.3.3) in which students measured the effects of distance on sound intensity level, students' worksheets included some data corresponding to measurements of incident and transmitted sound inside and outside a house (T1.3.4). Analyzing students' answers to T1.3.5, in which they interpreted how sound is attenuated, some progression could be noticed as a higher number of students seemed to hold a mental model that recognizes absorption as a mechanism of sound attenuation 
(S2 or S3). These results suggest that the experiment that students performed and the discussions that took place in class contributed to the revision of their mental models to fit the new empirical evidence.

In spite of this progression of students' mental models of sound attenuation in materials, our results also illustrate that most of their mental models (47\%) still belong to the first stage (S1) of development of CM1. Therefore, these results also emphasize the need for further activities to contribute to students' learning progression towards the construction of CM1. In this context, after students had expressed and revised their preliminary mental models, they were introduced to the scientific perspective and discussed it with their teacher and classmates. This activity seemed to have a strong positive effect in terms of promoting the revision of students' mental models as our results indicate that most of the students $(60 \%$ approximately) reached the fourth stage (S4) of the learning progression (i.e. the intended conceptual model of sound attenuation in materials).

Finally, the questions posed in the final assessment reveal that almost $40 \%$ of students seemed to hold a conceptual model of sound attenuation which corresponds to the third stage of development (S3) of CM1, whereas most of the students (about 60\%) were found to have been able to develop the intended conceptual model of sound attenuation CM1 (S4) at the end of the teaching sequence.

Influence of the activities of the TLS on students' learning progressions towards the construction of the conceptual model of sound attenuation in materials in terms of energy (CM1)

With the purpose of inferring the most representative students' learning progression towards the construction of CM1, we tracked each student's evolution throughout the TLS. Table 11 shows the types of evolution experienced by students while developing their mental models towards the intended conceptual model of sound attenuation in materials.

Table 11 Types of learning progressions experienced by students while developing CM1

\begin{tabular}{|c|ccc|}
\hline $\begin{array}{c}\text { Type of evolution of } \\
\text { students' models }\end{array}$ & $\begin{array}{c}\text { Before and after } \\
\text { the empirical } \\
\text { task }\end{array}$ & $\begin{array}{c}\text { Before and after } \\
\text { discussing the scientific } \\
\text { perspective }\end{array}$ & $\begin{array}{c}\text { Before and after } \\
\text { applying the model in } \\
\text { later tasks }\end{array}$ \\
\hline Progression & $29 \%$ & $\mathbf{8 4 \%}$ & $26 \%$ \\
Regression & $18 \%$ & $5 \%$ & $26 \%$ \\
No evolution & $\mathbf{5 3 \%}$ & $11 \%$ & $\mathbf{4 8 \%}$ \\
\hline
\end{tabular}

In general terms, these results highlight that the activities that students carried out to obtain new evidence from a hands-on experiment and to draw conclusions from it, and also the students' use of their revised mental models before the final assessment, promoted slight learning progress (29\% and $26 \%$ respectively). In contrast, the activity that had a greater impact on students' development of CM1 (84\%) was their engagement in the discussion with the teacher and classmates of the scientific perspective on sound attenuation in materials, which was introduced to students by means of a written text about how science interprets this phenomenon and a diagram representing how the energy of the incident sound is distributed when sound reaches an object.

\section{Students' development of the empirical conceptual model of the acoustic behavior of materials in terms of their physical properties (CM2)}

Students' achievement of each learning objective associated with the conceptual model of the acoustic behavior of materials in terms of their physical properties (CM2)

The findings of the analysis of students' achievement of learning objectives associated with the conceptual model of the acoustic behavior of materials in terms of their properties (CM2) at different moments of the implementation of the TLS are illustrated in Table 12.

Table 12 Learning objectives related to students' development of CM2

\begin{tabular}{|c|c|c|c|c|c|c|c|}
\hline $\begin{array}{l}\mathrm{LO}- \\
\mathrm{CM} 2\end{array}$ & T2.1.1 & T2.1.2.c & T2.1.3 & T2.1.6.b & T2.1.8 & Q4.a & Q5.a \\
\hline LO2.1 & $68 \%$ & $83 \%$ & $86 \%$ & $95 \%$ & - & $100 \%$ & $96 \%$ \\
\hline LO2.2 & $71 \%$ & $93 \%$ & $75 \%$ & $95 \%$ & - & $96 \%$ & $89 \%$ \\
\hline LO2.3 & $25 \%$ & $79 \%$ & $89 \%$ & $95 \%$ & - & $93 \%$ & $93 \%$ \\
\hline LO2.4 & $64 \%$ & $76 \%$ & $86 \%$ & $95 \%$ & $100 \%$ & $96 \%$ & $96 \%$ \\
\hline LO2.5 & $18 \%$ & $55 \%$ & $14 \%$ & $95 \%$ & $100 \%$ & $89 \%$ & $89 \%$ \\
\hline LO2.6 & $25 \%$ & $79 \%$ & $89 \%$ & $90 \%$ & $100 \%$ & $86 \%$ & $93 \%$ \\
\hline
\end{tabular}




\begin{tabular}{|l|lllllll|} 
LO2.7 & $0 \%$ & $0 \%$ & $18 \%$ & $95 \%$ & - & $89 \%$ & $64 \%$ \\
\hline
\end{tabular}

After students had gone through the first chapter of the TLS, intended to promote their development of the conceptual model of sound attenuation in materials in terms of energy (CM1), the second chapter started with an open-ended question to elicit their previous ideas on the acoustic behavior of materials (T2.1.1). As shown in Table 12, in the open-ended question, we found that more than two-thirds of students identified properties of materials roughly related to density (e.g. compactness) and to rigidity (e.g. hardness, elasticity) as acoustic properties of materials, i.e. as properties influencing the acoustic behavior of materials (LO2.1 \& LO2.2). Nevertheless, as reported in previous studies (Hernández et al. 2012; Linder, 1993), students often use similar scientific terms to refer to different properties of materials, attributing the same meaning to them. Such is the case with the terms dense used as a synonym for compact or heavy, and rigid used as a synonym for plastic, non-elastic, or hard. Moreover, at this point students attributed both extensive (e.g. thickness) and intensive (e.g. density) properties to the acoustic behavior of materials, using the word material as a synonym for object.

Later in the implementation, students discussed with their classmates the new terminology and perspectives introduced by the statements included in T2.1.2, and they were asked to formulate a consensus model of the acoustic behavior of materials in terms of their properties. As a result of this activity, most students (79\%) started attributing other properties to the acoustic behavior of materials, such as porosity (LO2.3). Nevertheless, in some cases students blurred the terms dense and little porous, as if the density of materials were uniquely related to their porosity.

When students predicted the acoustic behavior of samples of specific materials in T2.1.3, most of students (more than 75\%) identified properties related to density, rigidity and porosity of materials, among other characteristics, as influencing the acoustic behavior of materials (LO2.1, LO2.2 and LO2.3). Their difficulty with the accurate use of terminology (e.g. flexible as a synonym for elastic or soft) was again widely evidenced, however.

Later, students used a data-logging system connected to a sound level meter to test the acoustic behavior of the materials empirically. Next, in T2.1.6.b students were asked to describe the properties that all the tested sound reflectors have in common and also the properties that all the tested sound absorbers have in common. At this point, most of the students (about $90 \%$ ) not only were more accurate in terms of using the specific terms that refer to properties of materials influencing their acoustic behavior (LO2.4, LO2.5 and LO2.6) but they also reduced the number of properties that they associated with the acoustic behavior of materials. Thus, $95 \%$ of them only mentioned the three so-called acoustic properties of materials - density, rigidity, and porosity (LO2.7).

After discussing the scientific meaning of these properties and analyzing more accurately the properties of the tested materials, students wrote down their conclusions again on the properties of materials that characterize their acoustic behaviour (T2.1.8). At that point, all the students appropriately related density, rigidity and porosity of materials to their acoustic behaviour (LO2.4, LO2.5 and LO2.6).

In the final assessment, when students were asked to predict the acoustic behaviour of certain materials in Q4.a, about $90 \%$ of them did it uniquely in terms of density, rigidity and porosity relating them appropriately to the acoustic behavior of materials (LO2.7). In Q5.a, in which students were asked to identify in an advertisement of a product the properties that characterized it as a good sound absorber, most of them (about 90\%) mentioned density, rigidity and porosity. Some of them (about 30\%) also highlighted other characteristics of the material that make it a good product (e.g. durability). We interpret that the demand of Q5.a might not be clear enough as many students did not distinguished between the properties that made the material a good product from those properties that actually influenced its acoustic behavior making it a good sound absorber.

Students' stages of development of the conceptual model of the acoustic behavior of materials in terms of their physical properties (CM2) at each phase of the TLS

After characterizing each stage of development of CM2, we analysed the distribution of students in each stage of development of CM2 throughout the implementation of the teaching sequence. This distribution is represented in Figure 2. In order to analyze students' learning progressions at a grain size, we have also considered students' development of mental models in two additional phases of the implementation of the TLS, between students' elicitation of their preliminary mental models and students' revision of their mental models to be in agreement with the evidence obtained in the experiment. These two additional phases correspond to students' revision of their mental models after discussing new terminology and students' construction of an agreed preliminary model. 


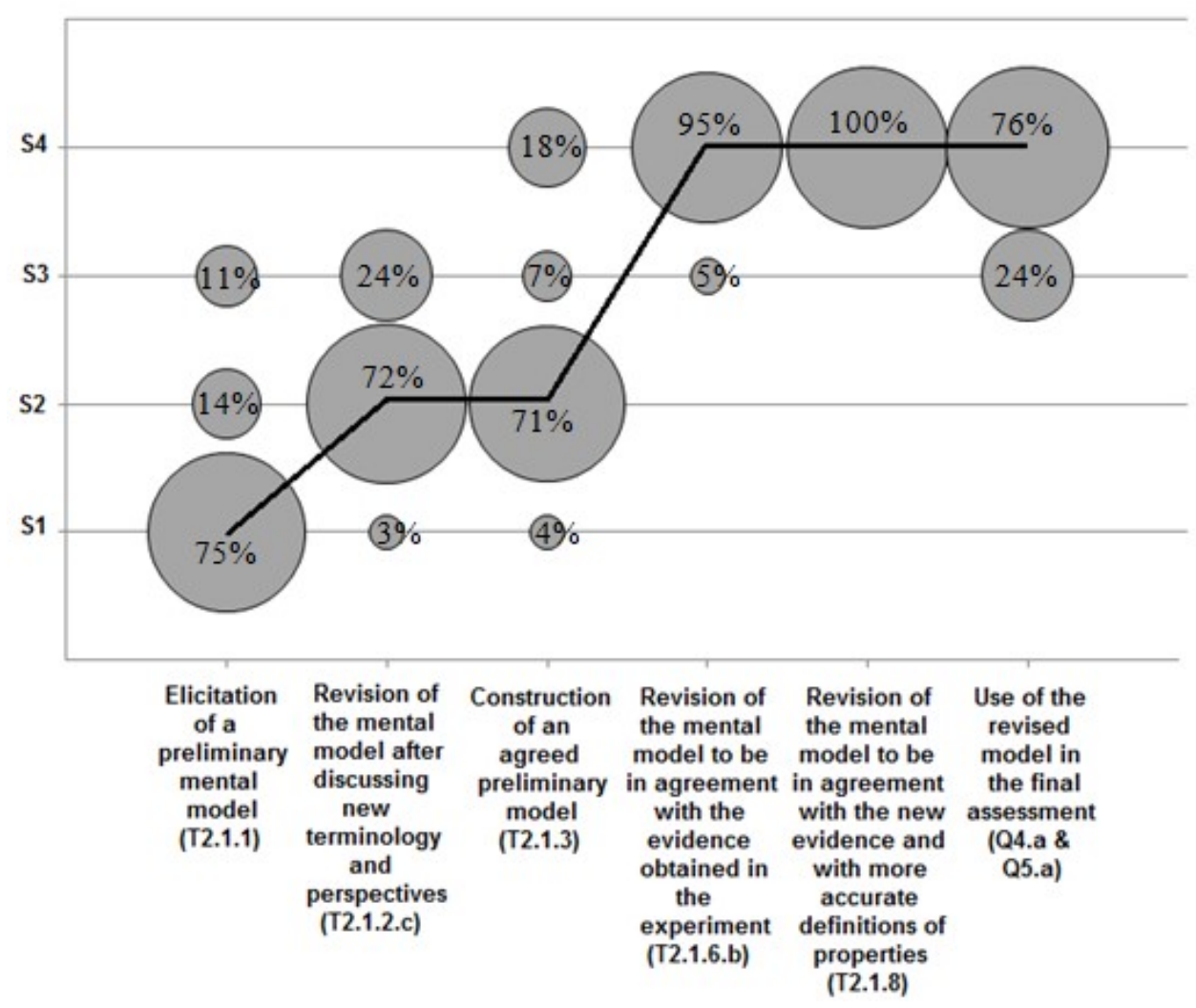

Fig. 2 Students' development of CM2 throughout the implementation of the TLS

Furthermore, Figure 2 shows the most representative students' learning progression towards the construction of the conceptual model of the acoustic behavior of materials in terms of their physical properties throughout the implementation of the TLS on APM. The most representative learning progression is highlighted with a straight line. The diameter of each circle represents the number of students in each stage of development of CM2 at different moments of the implementation of the TLS. Therefore, Figure 2 also shows that most students followed a certain learning progression whereas other students followed different learning progressions.

In Figure 2, we can see that as a starting point most students $(75 \%)$ related the acoustic behavior of materials to several intensive and extensive properties, such as density and rigidity, although these terms were not used appropriately (S1). After new terminology and perspectives were introduced and discussed (T2.1.2), more students started recognizing porosity as another acoustic property. In spite of mentioning these three key acoustic properties of materials, most of students (more than $70 \%$ ) still tended to blur certain scientific terms and also to associate many other characteristics with the acoustic behavior of materials (S2). In T2.1.3, after discussing the influence of certain properties on the acoustic behavior of materials and having reached a consensus model, most students seemed to hold a mental model that corresponded to the second stage of development (S2) of CM2.

The results from the analysis of students' answers to T2.1.6 show that, after students carried out the experiment to test the acoustic behavior of specific materials, almost all of them (95\%) adequately explained the acoustic behavior of materials uniquely in terms of intensive properties such as density, rigidity, and porosity, using these terms appropriately (S4). In the final assessment, most students $(76 \%)$ had developed the most elaborate version (S4) of CM2.

Influence of the activities of the TLS on students' learning progressions towards the construction of the conceptual model of the acoustic behavior of materials in terms of their physical properties (CM2)

With the purpose of inferring the most representative students' learning progression towards the construction of CM2, we tracked each student's evolution throughout the TLS. Table 13 shows the types of evolution experienced by students while developing their mental models towards the intended conceptual model of the acoustic behaviour of materials in terms of their physical properties (CM2).

Table 13 Types of learning progressions experienced by students while developing CM2 


\begin{tabular}{|c|ccccc|}
\hline $\begin{array}{c}\text { Type of } \\
\text { evolution of } \\
\text { students } \\
\text { models }\end{array}$ & $\begin{array}{c}\text { Before and } \\
\text { after discussing } \\
\text { new } \\
\text { terminology } \\
\text { and }\end{array}$ & $\begin{array}{c}\text { Before and } \\
\text { after } \\
\text { constructing } \\
\text { consensus } \\
\text { model }\end{array}$ & $\begin{array}{c}\text { Before } \\
\text { and after } \\
\text { the } \\
\text { empirical } \\
\text { task }\end{array}$ & $\begin{array}{c}\text { Before and after } \\
\text { analyzing more } \\
\text { accurate data and } \\
\text { discussing the } \\
\text { scientific meaning of } \\
\text { certain properties }\end{array}$ & $\begin{array}{c}\text { Before and } \\
\text { after } \\
\text { applying } \\
\text { the model } \\
\text { in later } \\
\text { tasks }\end{array}$ \\
\hline Progression & $\mathbf{7 5 \%}$ & $28 \%$ & $\mathbf{7 9 \%}$ & $0 \%$ & $0 \%$ \\
Regression & $7 \%$ & $18 \%$ & $0 \%$ & $0 \%$ & $14 \%$ \\
No evolution & $18 \%$ & $\mathbf{5 4 \%}$ & $21 \%$ & $\mathbf{1 0 0 \%}$ & $\mathbf{8 6 \%}$ \\
\hline
\end{tabular}

In general terms, these results highlight that students' discussion of new terminology and perspectives, introduced by means of certain statements (T2.1.2), and also students' engagement in performing and drawing conclusions from an experiment (T2.1.4, T2.1.5, and T2.1.6) had the greatest impact on students' development of CM2 as $75 \%$ and $79 \%$ of students respectively progressed from their mental models towards a more elaborate version after their engagement in each of these activities.

\section{Students' development of the theoretical conceptual model of the acoustic behavior of materials in terms of their internal structure (CM3)}

Students' achievement of each learning objective associated with the conceptual model of the acoustic behavior of materials in terms of their internal structure (CM3)

After students had gone through the activities intended to promote the development of CM2, they were engaged in other activities intended to promote their construction of CM3. The findings of the analysis of students' achievement of learning objectives associated with the conceptual model of the acoustic behavior of materials in terms of their internal structure (CM3) are illustrated in Table 14.

Table 14 Learning objectives related to students' development of CM3

\begin{tabular}{|c|ccccc|}
\hline LO - & T2.1.1 & T2.1.2 & $\begin{array}{c}\text { T2.2.2 \& T2.2.4 \& } \\
\text { CM3 }\end{array}$ & $\begin{array}{c}\text { T2.2.6 \& } \\
\text { T2.2.7 }\end{array}$ & Q5.b \\
\hline LO3.1 & $0 \%$ & $100 \%$ & - & $62 \%$ & $67 \%$ \\
LO3.2 & $0 \%$ & $54 \%$ & - & $62 \%$ & $63 \%$ \\
LO3.3 & $0 \%$ & $68 \%$ & - & $88 \%$ & $59 \%$ \\
LO3.4 & $0 \%$ & $18 \%$ & $79 \%$ & $42 \%$ & $56 \%$ \\
LO3.5 & $0 \%$ & $18 \%$ & $75 \%$ & $73 \%$ & $41 \%$ \\
\hline
\end{tabular}

As shown in Table 14, the results illustrate that all students related the acoustic behavior of materials to the internal structure of materials (LO3.1) only when they were asked to express their agreement or disagreement with certain statements about the influence of some characteristics such as the separation between particles on the acoustic behavior of materials (T2.1.2). Conversely, when the question was completely open (T2.1.1), students did not mention any characteristics related to the internal structure of materials as influencing their acoustic behavior.

When the students discussed with their classmates the new terminology and new perspectives introduced by the statements included in T2.1.2, more than half were able to relate density, rigidity or porosity of materials to their internal structure (LO3.2) and to use the particle model of matter to explain mechanisms of sound attenuation in materials (LO3.3). Nevertheless, almost half described density and rigidity in terms of distance between particles. Moreover, most of these students considered soundattenuating materials as sound barriers that prevent the passage of sound through them (Hernández et al. 2012).

After the thought experiment in which students used an analogy to investigate the influence of the internal structure of materials on their acoustic behavior, about $80 \%$ of them appropriately described density, rigidity or porosity of materials in terms of their microstructure (LO3.4), and $75 \%$ used the particle model of matter to appropriately explain mechanisms of sound attenuation in materials (LO3.5) in T2.2.2, T2.2.4 and T2.2.5. Thus, these students described the internal structure of materials in terms of the mass of their particles or the strength of the bonds between particles to explain sound attenuation in terms of more or less vibration of the particles that form each material.

Later in the implementation (T2.2.6 and T2.2.7), after discussion of the scientific perspective on how the properties of sound absorbers affect their acoustic behavior in terms of their microstructure, almost $75 \%$ of students used the particle model of matter appropriately to explain mechanisms of sound 
attenuation in materials (LO3.5). A lower number of students (62\%) described density, rigidity or porosity of materials in terms of their microstructure (LO3.2) and more than two-thirds of these students did it appropriately (LO3.4).

Similarly, in the final assessment (Q5.b) about 60\% of students were able to explain some mechanism of sound attenuation in materials using the particle model of matter and describing the internal structure of materials (LO3.2 and LO3.3). Almost $90 \%$ of these students appropriately described some acoustic properties of materials in terms of their microstructure (LO3.4), and about $70 \%$ appropriately explained sound attenuation in materials in terms of difficulty or ease of particle vibration (LO3.5).

Students' stages of development of the conceptual model of the acoustic behavior of materials in terms of their internal structure (CM3) at each phase of the TLS

After characterizing each stage of development of CM3, we analysed the distribution of students in each stage of development of CM3 throughout the implementation of the TLS on APM. This distribution is represented in Figure 3.

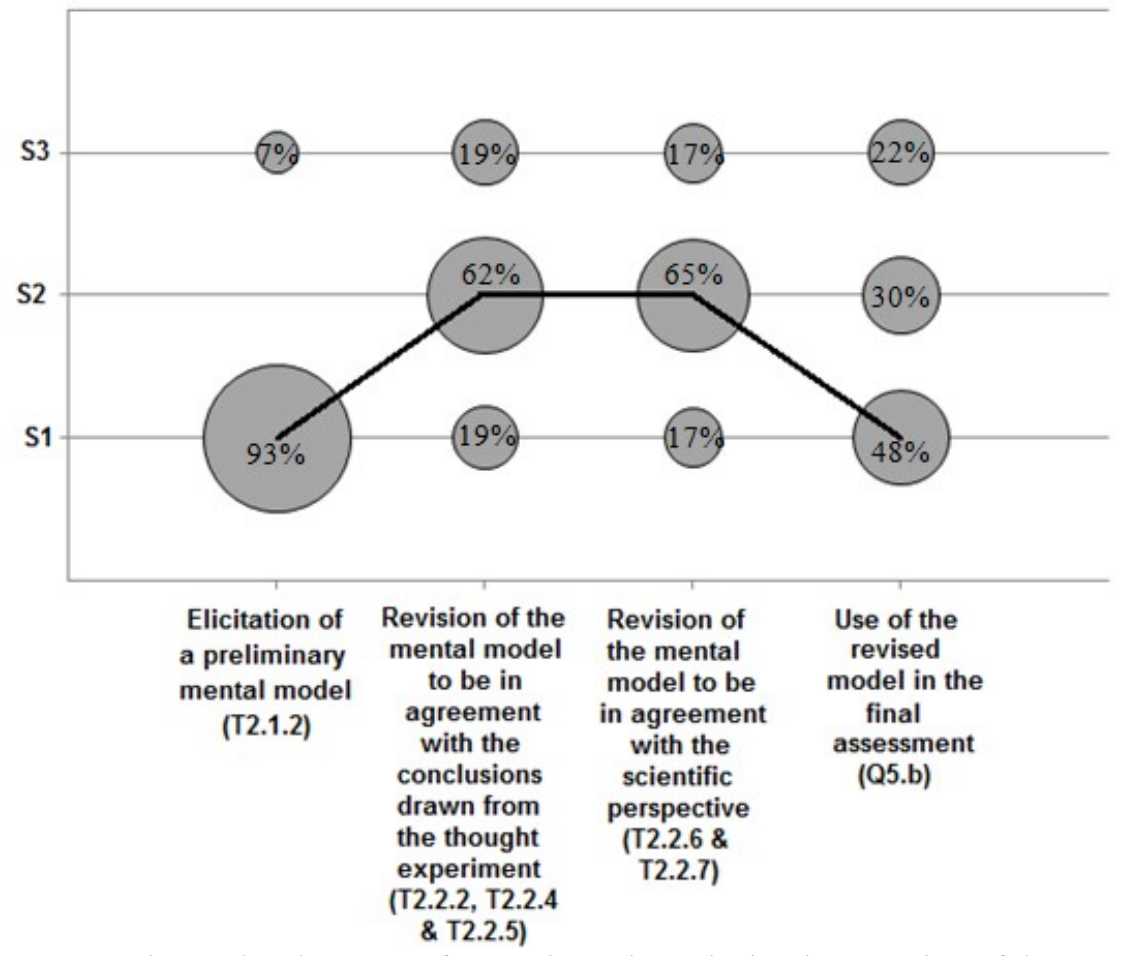

Fig. 3 Students' development of CM3 throughout the implementation of the TLS

Furthermore, Figure 3 shows the most representative students' learning progression towards the construction of the conceptual model of the acoustic behavior of materials in terms of their internal structure throughout the implementation of the TLS on APM. The most representative learning progression is highlighted with a straight line. The diameter of each circle represents the number of students in each stage of development of CM3 at different moments of the implementation of the TLS. Therefore, Figure 3 also shows that most students followed a certain learning progression whereas other students followed different learning progressions.

As shown in Figure 3, when students elicited their preliminary mental models in T2.1.2, more than $90 \%$ of students explained the acoustic behavior of materials using the particle model of matter and describing inadequate mechanisms of sound attenuation in materials. Nevertheless, the model expressed by these students (S1) was not consistent with the scientific perspective as it dealt with sound as an entity instead of as a process, and consequently sound attenuation was conceived as a process hindering the passage of sound or capturing sound instead of as a process of energy dissipation that involves vibration of particles.

After students had carried out the thought experiment described above, more than $80 \%$ started explaining the acoustic behavior of materials using the particle model of matter and appropriately explaining mechanisms of sound attenuation in materials (S3). Even though these students used the conceptual model (S3) to explain the influence of certain properties on the acoustic behavior of materials in terms of their internal structure, most of them also continued using the preliminary version of the 
model (S1) to explain the influence of other properties. That is to say, most of them used a hybrid mental model (S2). Similar results were evidenced after students were introduced to and discussed the scientific perspective in class with their teacher and classmates. In the final assessment, about half of the students answered in terms of S1 whereas the other half were found to use the more sophisticated version of the model (S3) or the hybrid version (S2).

Influence of the activities of the TLS on students' learning progressions towards the construction of the conceptual model of the acoustic behavior of materials in terms of their internal structure (CM3)

With the purpose of inferring the most representative students' learning progression towards the construction of CM3, we tracked each student's evolution throughout the TLS. Table 15 shows the types of evolution experienced by students while developing their mental models towards the intended conceptual model of the acoustic behaviour of materials in terms of their internal structure (CM3).

Table 15 Types of learning progressions experienced by students while developing CM3

\begin{tabular}{|c|ccc|}
\hline $\begin{array}{c}\text { Type of evolution } \\
\text { of students' } \\
\text { models }\end{array}$ & $\begin{array}{c}\text { Before and after performing } \\
\text { the thought experiment }\end{array}$ & $\begin{array}{c}\text { Before and after } \\
\text { discussing the } \\
\text { scientific perspective }\end{array}$ & $\begin{array}{c}\text { In the final } \\
\text { assessment }\end{array}$ \\
\hline Progression & $\mathbf{7 2 \%}$ & $29 \%$ & $21 \%$ \\
Regression & $4 \%$ & $24 \%$ & $\mathbf{5 3 \%}$ \\
No evolution & $24 \%$ & $\mathbf{4 8 \%}$ & $26 \%$ \\
\hline
\end{tabular}

The results expressed in Table 15 highlight that the students' realization and discussion with teacher and classmates of the thought experiment using an analogy was the activity that had a greater impact $(72 \%)$ in promoting the progression of students' mental models. The students' engagement in discussing the scientific perspective did not represent a significant activity in terms of promoting progression as the models of almost half of students remained the same after this activity. Finally, about $50 \%$ of students elicited a weaker version of their mental models in the final assessment.

\section{Discussion of Results}

The reported findings support the fact that experimenting with a TLS leads to two types of results (Méheut \& Psillos, 2004): results in terms of research validity and results in terms of pragmatic value. Consequently, to answer our two research questions, we will discuss the results described earlier in terms of their research validity (e.g. understanding modeling processes) and in terms of their pragmatic value (e.g. implications for teaching).

\section{On students' learning progressions from their preliminary mental models towards the intended conceptual models}

To answer our first research question, we discuss the learning processes that students underwent when developing their mental models for each of the three intended conceptual models dealt throughout the designed TLS on APM.

Concerning the stages of students' development of these three conceptual models, our results show that more than half of students reached the (theoretical) conceptual model of sound attenuation in materials in terms of energy (CM1), most of them reached the (empirical) conceptual model of the acoustic behavior of materials in terms of their physical properties (CM2), and about half of them reached the (theoretical) conceptual model of the acoustic behavior of materials in terms of their internal structure (CM3) or a hybrid version of this model. The remaining students reached lower stages of development for each of the three intended conceptual models. That is to say, all the students progressed through several stages of development of their mental models, and some of them reached the most elaborate version of each conceptual model.

In short, the conceptual model of the acoustic behavior of materials in terms of their physical properties (CM2) was developed by more students than the conceptual model of sound attenuation in materials in terms of energy (CM1) and, in turn, more students developed CM1 than the conceptual model of the acoustic behavior of materials in terms of their internal structure (CM3).

These differences can be interpreted in terms of the attributes of each conceptual model, in terms of the distance between students' preliminary mental models and the intended conceptual models, and in terms of the quality of the instruction that took place. In the words of Duschl et al. $(2011, \mathrm{p} .152)$, 'if the 
learning goals are too sophisticated or if the teaching sequence is ill conceived, then the intended learning outcomes run the risk of being too abstract or beyond the "boundaries" of outcome learning expectations for the targeted students'.

At this point, we will comment on the two first possible interpretations to account for these differences, and we will discuss the instructional issue later. As discussed earlier, the conceptual model of the acoustic behavior of materials in terms of their physical properties (CM2), as an empirical model, involves real entities (i.e. materials) and their observable properties. Taking into account that students' preliminary mental models often include macroscopic descriptions of natural objects or events, which are easily visible or related to their everyday experience (Tiberghien et al., 2009), we consider that in the case of this conceptual model (CM2) students' preliminary mental models could act as productive intuition for understanding, which can easily become more sophisticated through instruction.

By contrast, the theoretical models CM1 and CM3 consist of descriptions of unobservable events in terms of abstract entities such as energy and particles. Several research studies (e.g. Harrison \& Treagust, 2002; Millar, 2005) have reported a variety of difficulties in students' understanding of such concepts. The differences between students' development of the conceptual models CM1 and CM3 can be explained in terms of the distance between these conceptual models and students' preliminary mental models. In the case of CM1, students' preliminary mental models of sound attenuation reflect an intuitive view of the phenomenon of sound attenuation which is not inconsistent with the most elaborate version of the conceptual model. On the contrary, this intuition can be considered a simpler version of the intended conceptual model based on measurable magnitudes (e.g. sound intensity level) that students can later relate to an abstract entity such as energy. In the case of CM3, students' preliminary mental models already included abstract entities such as particles but these models conflicted with the conceptual model as they correspond to different models of sound (i.e. sound as an entity (Maurines, 1993; Hrepic, Zollman, \& Rebello, 2010) vs. sound as a process) and to different models of the structure of matter (i.e. properties described in terms of distance between particles vs. properties described in terms of mass of particles and strength of bonds between particles). That would explain the high percentage of students who, at the end of the implementation of the teaching sequence, used their preliminary mental models or a hybrid version of the model (i.e. using at the same time their preliminary mental model and the most elaborate version of the conceptual model). The fact that about $50 \%$ of students elicited their preliminary mental models of the acoustic behavior of materials in terms of their microstructure in the final assessment can be interpreted from other perspectives. This conceptual model (CM3) might be too demanding for the students at this level as it implies using the particle model of matter together with two other models: the model of sound attenuation in materials in terms of energy (CM1) and the model of acoustic behavior of materials in terms of their physical properties (CM2).

\section{On the salient modeling and inquiry activities of the TLS on APM}

Our second research question raises the issue of the role played by the modeling and inquiry activities of the TLS on APM, as implemented in class, in promoting students' evolution of their mental models towards the intended conceptual models.

The results showed that each of the three intended conceptual models entails different learning difficulties. This suggests that the design of the activities to promote the development of each of these conceptual models should differ from one to another.

Looking at the influence on students' learning progressions of the activities that they carried out (Figures 1, 2 and 3), we found that different types of modeling and inquiry activities played a decisive role in promoting students' development of each conceptual model. In the case of the theoretical model of sound attenuation in materials (CM1), our results indicate that the activity that seemed to facilitate more the development of students' mental models was the task in which students discussed with their teacher and classmates the scientific perspective introduced by means of a text and a diagram (i.e. 'What does science tell us?'). However, we suggest that the influence of this activity cannot be interpreted in an isolated way. Rather, we assume that this activity had a greater impact on students' development of CM1 taking into account the attributes of this conceptual model as a theoretical model, and the activities that students had previously carried out (i.e. eliciting their preliminary mental models, obtaining new evidence from an experiment and drawing conclusions from it).

In the case of the empirical model of the acoustic behavior of materials in terms of their physical properties (CM2), the activity that seemed to facilitate more a positive development of students' mental models was the task in which students carried out an experiment and drew conclusions from the new evidence obtained. Another activity that also seemed to have a positive impact on students' development of mental models was the task in which they were asked to reach a consensus model, once they had 
individually elicited their preliminary mental models and had explored new terminology and different perspectives from provided statements.

Finally, in the case of the theoretical model of the acoustic behavior of materials in terms of their internal structure (CM3), the activity that seemed to facilitate more the development of students' mental models was the task in which students carried out a thought experiment using an analogy and drew conclusions from it. Comparing students' evolution of CM3 to students' evolution of CM1, which we have also considered to be a theoretical conceptual model, one might wonder about their differences: most of students made positive progress after discussing the scientific perspective for CM1, whereas only a small portion of students did so for CM3. One possible interpretation is that regarding CM3, most students had already had a positive progression after performing the thought experiment and so, later, after discussing the scientific perspective, most students continued holding the same mental models they had already developed. In the case of CM1, the situation is different since after the empirical task, most of the students' mental models remained the same as before, and later, after discussing the scientific perspective, most students' mental models evolved towards more elaborate mental models. Finally, the poor results of students' development of CM3 make us wonder whether a different approach to the use of the analogy would have resulted in a more positive learning progression. Other possible interpretation of the fact that about $50 \%$ of students elicited their preliminary mental models of the acoustic behavior of materials in terms of their microstructure in the final assessment might be the lack of application of this conceptual model (CM3) in different situations throughout the teaching sequence, which might have contributed to the lack of consolidation of this model at the end of the implementation of the TLS.

\section{Conclusions and implications for design, research and instruction}

Tracking students' learning progressions throughout the TLS has turned out to be a very useful methodological procedure for studying students' development of conceptual models and the influence of the activities of the designed TLS on APM. Thus, we consider it an appropriate method for carrying out specific research studies within the design-based research paradigm.

We have found that the different intended conceptual models involve different learning demands (Leach \& Scott, 2002), which we have interpreted in terms of the attributes (theoretical or empirical) of each model, in terms of the distance between students' preliminary mental models and the intended conceptual models, and in terms of instructional activities. Moreover, in this study we have characterized students' development of mental models towards the intended conceptual models throughout different stepping stones or stages of development of the conceptual model. This result backs the importance of intermediary steps in supporting student understanding. One important implication for teaching and design is that the empirically-based students' learning progressions, expressed as increasingly sophisticated versions of each conceptual model, can help teachers monitor or assess how many students progress in what they are learning in real contexts and adapt their instruction in response to students' evolution and needs in order to support student learning. Thus, these learning progressions should be further investigated in classroom settings in order to empirically validate or adapt them to other educational conditions in the light of research (Duschl et al., 2011).

In any case, we cannot forget that there is no single learning progression that leads students to develop intended conceptual models but multiple ways in which they can reach understanding. In line with this, we recognize that students' learning outcomes at the end of the designed teaching sequence are not to be seen as an end point but as an intermediate one, and require further support and instruction so that students continue learning.

Regarding the design principles related to the types of activities of the MBI approach of the TLS on APM, we have gained an insight into the role played by the different types of modeling and inquiry activities in promoting students' development of conceptual models throughout the TLS. According to our results and the research design, we cannot generalize any pattern of influence of the inquiry and modeling activities of the designed teaching sequence on students' learning progressions. We have evidenced that the tasks involving class group discussion on the scientific perspective and the tasks involving thought experiments seem to play a more significant role in contributing to students' development of theoretical models. On the other hand, the tasks involving ICT-supported hands-on experiments and class group discussions on other classmates' perspectives introducing new terminology and ideas seem to have greater impact in promoting students' development of empirical models. By tasks involving class group discussion on the scientific perspective, we do not mean transmissive teaching in which the scientific perspective is introduced by the teacher or the material as a process of communication in a one-way direction. Rather, we refer to guided or oriented activities in which teachers and students discuss and try to reconcile different perspectives and meanings of terms. Regarding the ICT-supported hands-on experiments, it is important to emphasize that these experiments have been 
feasible because of the use of data capture systems such as the sound level meter. These experiments are thus good examples of how ICT tools can contribute to the development of an empirical conceptual model, which otherwise might not have been developed through experimental work. In any case, we consider that tasks involving students' elicitation of the preliminary or revised mental models are also essential to contribute to students' learning progressions throughout the TLS on APM.

Regarding the design principles related to the structure of each sequence of tasks, our results support that the sequence of activities including students' elicitation of their own prior knowledge, followed by their involvement in inquiry tasks and later discussion of and comparison with the scientific perspective, has a positive impact in terms of contributing to students' development of their mental models. Therefore, we highlight the importance of including such kinds of different tasks prior to any classroom discussion of the scientific perspective when a TLS is designed. That is to say, students should be put in the situation of eliciting their own mental models and feeling the need to revise them in agreement with the new (empirical or non-empirical) evidence obtained (from real or thought experiments) before the scientific perspective or intended conceptual model is introduced, discussed and compared to preliminary mental models.

In short, these results highlight that the relationship between modeling and inquiry is complex as different modeling and inquiry activities seem to facilitate students' development of a certain type of conceptual model but they need to be combined and appropriately sequenced to become effective. Further research is necessary to better understand the interplay between modeling and inquiry processes in teaching and learning science, and about science.

\section{References}

Acher, A., Arcà, M., \& Sanmartí, N. (2007). Modeling as a teaching learning process for understanding materials: A case study in primary education. Science Education, 91, 398-418.

Anderson, R. D. (2002). Reforming science teaching: What research says about inquiry. Journal of Science Teacher Education, 13(1), 1-12.

Barrow, L. H. (2006). A brief history of inquiry: From Dewey to standards. Journal of Science Teacher Education, 17, 265-278.

Buckley, B. (2000). Interactive multimedia and model-based learning in biology. International Journal of Science Education, 22 (9), 895-935.

Bunge, M. (1973). Method, model and matter. Holland: D. Reidel Publishing Company: Dordrecht.

Buty, C., Tiberghien, A., \& Le Maréchal, J. F. (2004). Learning hypotheses and an associated tool to design and to analyse teaching-learning sequence. International Journal of Science Education, 26(5), 579-604.

Campbell, T., Zhang, D., \& Neilson, D. (2011). Model based inquiry in the high school physics classroom: An exploratory study of implementation and outcomes. Journal of Science Education and Technology, 20(3), 258-269.

Chinn, C., \& Malhotra, B. (2002). Epistemologically authentic inquiry in schools: A theoretical framework for evaluating inquiry tasks. Science Education, 86, 175-218.

Clement, J. (2000). Model based learning as a key research area for science education. International Journal of Science Education, 22(9), 1041-1053.

Couso, D. (in press). Participatory approaches on curriculum design. In: Psillos, D., Kariotoglou, P. (eds) Iterative design of teaching-learning sequences: introducing the science of materials in European schools. Springer Editorial.

Corcoran, T., Mosher, F.A., \& Rogat, A. (2009). Learning progressions in science: An evidence-based approach to reform. Consortium for Policy Research in Education Report \#RR-63. Philadelphia, PA: Consortium for Policy Research in Education.

Design-Based Research Collective. (2003). Design-based research: An emerging paradigm for educational inquiry. Educational Researcher, 32(1), 5-8.

Driver, R., Leach, J., Scott, P., \& Wood-Robinson, C. (1994). Young people's understanding of science concepts: Implications of cross-age studies for curriculum planning. Studies in Science Education, 24, 75-100.

Duit, R., Gropengießer, H., \& Kattmann, U. (2005). Towards science education research that is relevant for improving practice: The model of educational reconstruction. In H.E. Fischer, (Ed.), Developing standards in research on science education (pp. 1-9). London: Taylor \& Francis.

Duschl, R., Maeng, S., \& Sezen, A. (2011). Learning progressions and teaching sequences: a review and analysis. Studies in Science Education, 47(2), 123-182. 
Giere, R. N. (1999). Using models to represent reality. In L. Magnani, N. J. Nersessian, \& P. Thagard (Eds.), Model-based reasoning in scientific discovery (pp. 41-57). New York: Kluwer Academic/Plenum Press.

Gilbert, J., \& Boulter, C. (1998). Learning science through models and modelling. In B. J. Fraser \& K. G. Tobin (Eds.), International handbook of science education, Part 1 (pp.53-66). Dordretch, Netherlands: Kluwer Academic Publishers.

Gobert, J., \& Buckley, B. (2000). Introduction to model-based teaching and learning in science education. International Journal of Science Education, 22(9), 891-894.

Greca, I. M., \& Moreira, M. A. (2000). Mental models, conceptual models, and modelling. International Journal of Science Education, 22(1), 1-11.

Harrison, A. G., \& Treagust, D. F. (2002). The particulate nature of matter: challenges in understanding the submicroscopic world. In J. K. Gilbert, O. de Jong, R. Justi, D. F. Treagust, \& J. H. van Driel (Eds.), Chemical education: Towards research-based practice (pp.189-212). The Netherlands: Kluwer Academic.

Hernández, M.I., Couso, D., Pintó, R. (2011). Teaching acoustic properties of materials in secondary school: testing sound insulators. Physics Education, 46(5):559-569.

Hernández, M.I., Couso, D., Pintó, R. (2012). The analysis of students' conceptions as a support for the design of a teaching/learning sequence on acoustic properties of materials. Journal of Science Education \& Technology, 21(6):702-712.

Hernández, M.I., Pintó, R. (in press). The process of iterative development of a teaching/learning sequence on acoustic properties of materials. In: Psillos, D., Kariotoglou, P. (eds). Iterative design of teaching-learning sequences: introducing the science of materials in European schools. Springer Editorial.

Hrepic, Z., Zollman, D., \& Rebello, S. (2010). Identifying students' mental models of sound propagation: The role of conceptual blending in understanding conceptual change. Physical Review Special Topics - Physics Education Research, 6, 1-18.

Izquierdo-Aymerich, M., \& Adúriz-Bravo, A. (2003). Epistemological foundations of school science. Science \& Education, 12(1), 27-43.

Justi, R., \& Gilbert, J. (2002). Modelling, teachers' views on the nature of modelling, and implications for the education of modellers. International Journal of Science Education, 24(4), 369-387.

Khan, S. (2007). Model-based inquiries in chemistry. Science Education, 91, 877-905.

Koponen, I. T. (2007). Models and modelling in physics education: A critical re-analysis of philosophical underpinnings and suggestions for revisions. Science \& Education, 16, 751-773.

Leach, J., \& Scott, P. (2002). Designing and evaluating science teaching sequences: An approach drawing upon the concept of learning demand and a social constructivist perspective on learning. Studies in Science Education, 38, 115-142.

Lehrer, R., Schauble, L., \& Lucas, D. (2008). Supporting development of the epistemology of inquiry. Cognitive Development, 23, 512-529.

Lijnse, P., \& Klaassen, K. (2004). Didactical structures as an outcome of research on teaching-learning sequences? International Journal of Science Education, 26(5), 537-554.

Linder, C.J. (1993). University physics students' conceptualizations of factors affecting the speed of sound propagation. International Journal of Science Education, 15(6), 655-662.

Löhner, S., van Joolingen, W. R., Savelsbergh, E. R., \& van Hout-Wolters, B. (2005). Students' reasoning during modeling in an inquiry learning environment. Computers in Human Behavior, 21, 441-461.

Louca, L. T., Zacharia, Z. C., \& Constantinou, C. P. (2011). In quest of productive modeling-based learning discourse in elementary school science. Journal of Research in Science Teaching, 48(8), 919951.

Maurines, L. (1993). Spontaneous reasoning on the propagation of sound. In J. Novak (Ed.), Proceedings of the third international seminar on misconceptions and educational strategies in science and mathematics. Ithaca, NY: Cornell University.

Méheut, M., \& Psillos, D. (2004). Teaching-learning sequences: Aims and tools for science education research. International Journal of Science Education, 26(5), 515-535.

Mellar, H., \& Bliss, J. (1994). Introduction: Modelling and education. In H. Mellar, J. Bliss, R. Boohan, J. Ogborn \& C. Thompsett (Eds.), Learning with artificial worlds: Computer based modelling in the curriculum (pp. 1-7). London: The Falmer Press.

Millar, R. (2005). Teaching about energy. Department of Educational Studies, Research Paper, 11. York: The University of York. 
Minner, D., Levy, A. J., \& Century, J. (2010). Inquiry-based science instruction - What is it and does it matter? Results from a research synthesis years 1984 to 2002. Journal of Research in Science Teaching, 47(4), 474-496.

Nersessian, N. J. (1995). Should physicists preach what they practice? Constructive modeling in doing and learning physics. Science \& Education, 4(3), 203-226.

Nersessian, N. J. (1999). Model-based reasoning in conceptual change. In L. Magnani, N. J. Nersessian \& P. Thagard (Eds.), Model-based reasoning in scientific discovery (pp. 5-22). New York: Kluwer Academic/Plenum Press.

Niedderer, H., \& Goldberg, E. (1995). Learning pathway and knowledge construction in electric circuits. Paper presented at the First European Conference on Research in Science Education. Leeds, UK.

Norman, D. (1983). Some Observations on Mental Models. In D. Gentner \& A. Stevens (Eds.), Mental Models. New Jersey: Lawrence Erlbaum Associates.

Oh, P. S., \& Oh, S. J. (2011). What teachers of science need to know about models: An overview. International Journal of Science Education, 33(8), 1109-1130.

Pintó, R. (2005). Introducing curriculum innovations in science: identifying teachers' transformations and the design of related teacher education. Science Education, 89(1):1-12.

Pintó, R., Couso, D., Hernández, M.I., Armengol, M., Cortijo, C., Martos, R., Padilla, M., Rios, C., Simón, M., Sunyer, C., Tortosa, M. (2010). Acoustic properties of materials: teachers' manual and teaching and learning activities. Nicosia, Cyprus.

Rea-Ramirez, M. A., Clement, J., \& Núñez-Oviedo, M. C. (2008). An instructional model derived from model construction and criticism theory. In J. Clement \& M. A. Rea-Ramirez (Eds.), Model based learning and instruction in science. (pp. 23-43) Dordrecht: Springer.

Ruthven, K., Laborde, C., Leach, J., \& Tiberghien, A. (2009). Design tools in didactical research: Instrumenting the epistemological and cognitive aspects of the design of teaching sequences. Educational Researcher, 38(5), 329-342.

Schwarz, C. V., \& Gwekwerere, Y. N. (2007). Using a guided inquiry and modeling instructional framework (EIMA) to support preservice K-8 science teaching. Science Education, 91, 158-186.

Schwarz, C. V., Reiser, B. J., Davis, E. A., Kenyon, L., Acher, A., Fortus, D., Shwartz, Y., Hug, B., \& Krajcik, J. (2009). Developing a learning progression for scientific modeling: Making scientific modeling accessible and meaningful for learners. Journal of Research in Science Teaching, 46(6), 632-654.

Scott, P. H. (1992). Conceptual pathways in learning science: A case study of the development of one student's ideas relating to the structure of matter. In R. Duit, F. Goldberg \& H. Niedderer (Eds), Research in physics learning: Theoretical issues and empirical studies (pp. 203-224). Kiel: IPN.

Stewart, J., Cartier, J. L., \& Passmore, C. M. (2005). Developing understanding through model-based inquiry. In M. S. Donovan \& J. D. Bransford (Eds.), How students learn (pp. 515-565).Washington D.C.: National Research Council.

Talanquer, V. (2009). On cognitive constraints and learning progressions: The case of "structure of matter". International Journal of Science Education, 31(15), 2123-2136.

Tiberghien, A. (1994). Modeling as a basis for analyzing teaching-learning situations. Learning and Instruction, 4, 71-87.

Tiberghien, A., Vince, J., \& Gaidioz, P. (2009). Design-based research: Case of a teaching sequence on mechanics. International Journal of Science Education, 31(17), 2275-2314.

Viennot, L. (2010). Physics education research and inquiry-based teaching: A question of didactical consistency. In K. Kortland \& K. Klaassen (Eds.), Designing theory-based teaching-learning sequences for science education; Proceedings of the symposium in honour of Piet Lijnse at the time of his retirement as professor of physics didactics at Utrecht University (pp. 37-54). Utrecht: CDBeta Press.

Viennot, L., Chauvet, F., Colin, P., \& Rebmann, G. (2005). Designing strategies and tools for teacher training: The role of critical details, examples in optics. Science Education, 89, 13-27.

Viennot, L., \& Rainson, S. (1999). Design and evaluation of a research-based teaching sequence: the superposition of electric field. International Journal of Science Education, 21(1), 1-16.

Wells, M., Hestenes, D., \& Swackhamer, G. (1995). A modeling method for high school physics instruction. American Journal of Physics, 63(7), 606-619.

Windschitl, M., Thompson, J., \& Braaten, M. (2008). Beyond the scientific method: Model-based inquiry as a new paradigm of preference for school science investigations. Science Education, 92, 941-967. 